\title{
A review of microstructure, mechanical properties and wear behavior of hybrid aluminium matrix composites fabricated via stir casting route
}

\author{
JASWINDER SINGH ${ }^{1}$ and AMIT CHAUHAN ${ }^{2, *}$ \\ ${ }^{1}$ University Institute of Engineering and Technology, Panjab University SSG Regional Centre, \\ Hoshiarpur 146023, India \\ ${ }^{2}$ University Institute of Engineering and Technology, Panjab University, Chandigarh 160014, India \\ e-mail: jaswinder_80@yahoo.co.in; drchauhan98@gmail.com
}

MS received 25 May 2015; revised 15 November 2018; accepted 16 November 2018; published online 2 January 2019

\begin{abstract}
This article focuses on the mechanical and wear properties of the Al-based hybrid composites fabricated by stir casting route. A wide range of literature has been consulted in this regard and it has been revealed that processing conditions can be tailored to obtain homogeneous structure of the Al-composites. The addition of ceramic particles has been found to be essential to provide requisite strength and hardness to these composites. Also, use of agro/industrial waste materials such as fly ash, red mud and rice husk ash as a complementary reinforcement reduces the density of the hybrid composites without compromising the mechanical properties. The literature review also indicates that addition of soft reinforcements along with hard reinforcements reduces the brittleness of the hybrid composites. Moreover, the presence of solid lubricants like graphite significantly improves the wear resistance of these materials. It has been noticed that incorporation of solid lubricants also helps in the formation of a protective tribolayer at the interface thereby reducing the wear rate and plastic deformation of these composites. In overall, study concludes that Al-based hybrid composites have great promise to serve as a substitute to the ceramic reinforced composites and the unreinforced Al-alloys in various automotive applications requiring low cost, high strength-to-weight ratio and superior wear resistance.
\end{abstract}

Keywords. Aluminium matrix composite (AMCs); hybrid reinforcements; ceramics; agro/industrial waste; mechanical properties; sliding wear.

\section{Introduction}

During the last decade, demand for new generation materials has considerably increased in the transportation sector due to increasing fuel economy requirements, strict environmental regulations and increasing customer demands. To meet these requirements, the industrial organizations are focusing on development of lightweight and eco-friendly materials. Previous work has reported that aluminum matrix composites (AMCs) exhibit superior characteristics such as high specific strength and stiffness, low density, low coefficient of thermal expansion and superior abrasive wear resistance [1-3]. It has been reported that a remarkable enhancement in the performance of the Al-composites can be achieved by inclusion of even a small percentage of ceramic reinforcements [4, 5]. Further, characteristics of these materials can be adjusted by varying percentage of reinforcement phase and selection of appropriate processing route. Currently, development of discontinuously

*For correspondence reinforced AMCs has been found to be an attractive option for the researchers and the scientists. This may be due to economic viability, nearly homogeneous structure and simplicity for processing of the AMCs reinforced with particulate reinforcements. These materials can also be subjected to a number of forming processes like forging, extrusion and rolling in order to improve the uniformity of reinforcement particles and interfacial strength of the composites $[6,7]$.

It has been revealed that use of innovative techniques for fabrication of AMCs is quite helpful in meeting various service requirements such as lifetime requirements, complexity of shape, strength considerations and cost requirements. Now a days, liquid casting route has been found to be most viable option for production of Al-composites on a commercial scale since it is simple, economical, flexible and highly productive method [8,9]. In this process, the reinforcements are incorporated into the molten alloy by stirring action of the impeller followed by casting of the composites. In this method, the processing parameters such as feed rate, stirring time and temperature and preheating 
temperature of the reinforcements can be controlled to obtain adequate microstructural properties of these composites [10]. Actually, particle clustering is a common phenomenon in the cast-composites that can reduce the strength and the wear resistance of the AMCs. It has been noticed that casting of the composites in a semi-solid state considerably reduces particle clustering in these composites $[11,12]$. The relative movements of the reinforcement particles in the liquid alloy (due to density gradient) are considerably reduced in the semi-solid casting process that further reduces the particle clustering in the composites. Thus, interfacial properties of the composites are improved that results in an increase in the mechanical strength of the AMCs. This shows that stir casting process can be modified according to requirements so as to obtain nearly net-shape of the composite specimens [13].

It has also been reported that aggregate properties of the Al-composites depend on type and fraction of reinforcement materials. Different types of reinforcements are being used by the researchers to improve the strength of the Almatrices. Generally, particulate reinforcements used for development of these composites can be classified into two broad categories [14]: hard reinforcements such as silicon carbide $(\mathrm{SiC})$, alumina $\left(\mathrm{Al}_{2} \mathrm{O}_{3}\right)$, boron carbide $\left(\mathrm{B}_{4} \mathrm{C}\right)$, titanium carbide $(\mathrm{TiC})$ and silica $(\mathrm{SiC})$ particles with elastic modulus greater than $30 \mathrm{GPa}$ and soft reinforcements such as $\mathrm{Gr}, \mathrm{MoS}_{2}$ and $\mathrm{TiO}_{2}$ particles having elastic modulus lower than $2 \mathrm{GPa}$. The inclusion of hard particles into soft Al-matrices increases their hardness, wear resistance and thermal characteristics, while presence of soft particles makes these materials self-healing and self-lubricating in nature [15]. Now a days, use of agro/industrial waste products as a particulate reinforcement has been considered to be an economically viable option since these are abundantly available in the country [16, 17]. Moreover, these materials are usually dumped in open land leading to environmental pollution. Therefore, utilization of waste materials in the AMCs industry can be helpful in reducing the environmental hazards related to disposal of these materials [18, 19].

Although, the specific strength, stiffness and wear resistance of soft Al-alloys are significantly increased with addition of the ceramic particles, but a number of limitations have also been reported with regard to use of $\mathrm{Al} /$ ceramics composites [18]. It has been revealed that addition of ceramic particles increases the density of the resultant composites. This may be attributed to higher density of ceramic reinforcements such as $\mathrm{SiC}$ (of the order of $3.22 \mathrm{~g} / \mathrm{cm}^{3}$ ) and $\mathrm{Al}_{2} \mathrm{O}_{3}$ (of the order of $3.9 \mathrm{~g} / \mathrm{cm}^{3}$ ) in comparison to Al-matrices (with a density of $2.7-2.8 \mathrm{~g} / \mathrm{cm}^{3}$ ). Moreover, the ceramic particles exhibit higher elastic modulus (of the order of $400 \mathrm{GPa}$ ) compared with the Alalloys (of the order of $70 \mathrm{GPa}$ ). This results in degradation of the aggregate properties such as brittleness, machinability and fracture toughness of the AMCs [20-22]. Also, soft materials like agroindustrial waste and lubricant particles are unlikely to be considered as a single reinforcement for development of the Al-composites for high stress bearing applications. This may be attributed to the fact that agro/ industrial waste materials exhibit elastic modulus of the order of $60-70 \mathrm{GPa}$, which is similar to that of $\mathrm{Al}(60 \mathrm{GPa})$ [18].

Under these circumstances, development of hybrid aluminium matrix composites (HAMCs) has been found to be quite beneficial [23-26]. In these materials, high strength and wear capabilities of ceramic particles are combined with light weight, low cost and lubricating properties of the secondary reinforcements. It has been revealed that the presence of lubricating particles considerably reduce the wear rate of the HAMCs. Also, use of agro/industrial waste products can reduce the cost/weight of the hybrid composites without compromising their mechanical properties. But, lack of knowledge regarding service performance and utilization options can limit wider use of these composites. Therefore, it is essential to review mechanical and wear properties of these materials (HAMCs) containing different combinations of reinforcement materials.

Keeping all these issues in mind, succeeding sections present the literature review regarding development of low cost hybrid Al-composites using an economic processing technique i.e., stir casting route. Also, microstructural, mechanical and wear properties of developed HAMCs have been critically reviewed and the underlying mechanisms have been elaborated in detail. In overall, this paper has been organized into six sections: The first section gives brief introduction about the AMCs with special reference to HAMCs. In second section, reinforcement materials and their chemical compositions have been elaborated. The third section discusses the properties of HAMCs reinforced with ceramic particulates and industrial waste materials. The fourth section includes the discussion regarding properties of HAMCs reinforced with ceramics particles and agro-waste ashes. In fifth section, the properties of HAMCs reinforced with ceramics and lubricant particles have been critically reviewed. In sixth section, the concluding remarks of the study have been elucidated.

\section{A brief description of the reinforcement materials for development of HAMCs}

\subsection{Primary ceramic reinforcements}

The ceramics are the materials that can be employed in various engineering applications requiring exceptional thermal stability and resistance to chemical attack at a higher temperature and chemical purity. Nowadyas, micron-sized $\mathrm{SiC}$ and $\mathrm{Al}_{2} \mathrm{O}_{3}$ particulates are widely used to improve the strength, wear performance and thermal resistance of the Al-alloys [27, 28]. This may be attributed to the fact that these particles have been found to be chemically compatible with the Al-matrices. Due to this, 
these reinforcements form a strong bond within the Almatrix without developing intermetallic phases. Therefore, a considerable change in the mechanical characteristics of the Al-composites has been noticed during application of external loads. The increased brittleness of the ceramic reinforced composites is the major problem that can be reduced to certain extent by using a number of secondary reinforcements.

\subsection{Secondary reinforcements}

2.2a Fly ash (FA): FA is a waste material that is produced during combustion of coal in the power plants. As coal is a major source of power generation in India, thus FA is available in large quantities throughout the country. Moreover, FA exhibit low density (1.79-2.89 g/ $\left.\mathrm{cm}^{3}\right)$, high strength, and superior corrosion resistance due to which it has been used as a reinforcement material in the AMCs [29]. The main constituents of FA include $\mathrm{Al}_{2} \mathrm{O}_{3}$ (29.9\%), $\mathrm{SiO}_{2}(56.92 \%), \mathrm{Fe}_{2} \mathrm{O}_{3}(8.44 \%), \mathrm{TiO}_{2}(2.75 \%)$ and carbon/ loss of index (1.99\%) [30]. Generally, FA reinforced composites are called 'Ash alloys' and these exhibit superior properties in comparison to unreinforced alloys. The previous reports have indicated that utilization of FA as a reinforcement material in AMCs industry will lead to reduction in environmental emissions and energy savings in the automotive industry [31].

2.2b Red mud (RM): RM is another insoluble waste product that is obtained from aluminum industry in large quantities. It is generated in the Bayer's process during production of alumina from the ore (bauxite). The storage, disposal and utilization of this material are the major challenges for the industrial organizations and environmentalists. The $\mathrm{Al}_{2} \mathrm{O}_{3}$ (20.80\%), $\mathrm{SiO}_{2}(22.35 \%), \mathrm{Fe}_{2} \mathrm{O}_{3}$ (7.73\%), $\mathrm{TiO}_{2}$ (4.98\%), $\mathrm{CaO}(18.51 \%)$ and $\mathrm{Na}_{2} \mathrm{O}(8.83 \%)$ are the major constituents of the RM [32]. The low cost, easy availability and chemical nature of this material are some of the reasons that make it suitable as a reinforcement material for development of AMCs [33].

2.2c Zircon tailing sand (ZTS): This is a waste material that can be collected from manufacturers supplying $\mathrm{Zr}$ to nuclear reactors and aerospace industry [10]. The abundant but useless ZTS is usually dumped in designated landfills leading to a number of environment related problems. Utilizing the ZTS in AMCs industry is quite beneficial for the cost reduction and solid waste treatment. The main constituents of the ZTS particles are $\mathrm{SiO}_{2}$ and aluminum silicate $\left(\mathrm{Al}_{2} \mathrm{SiO}_{5}\right)$ that is an indication of suitability as a reinforcement material.

2.2d Rice husk ash (RHA): Rice husk is an agro waste material that is obtained during milling of the paddy in the rice mills. Generally, it is used as a fuel in the rice mills for generating electricity. It has been noticed that $25 \%$ of the total weight of rice husk is converted into the ash during steam generation process. The RHA has posed a major threat to the environment since it is usually dumped in the open land. The researchers are using this material in developing high performance AMCs due to its low density $\left(0.3-1.9 \mathrm{gm} / \mathrm{cm}^{3}\right)$ and easy availability [18]. The major constituent of RHA is $\mathrm{SiO}_{2}(97.09 \%)$ along with other refractory elements such as $\mathrm{Al}_{2} \mathrm{O}_{3}$ (1.135\%), $\mathrm{MgO}$ $(0.825 \%)$ and $\mathrm{Fe}_{2} \mathrm{O}_{3}(0.31 \%)[34,35]$.

2.2e Coconut Shell Ash (CSA): This agro waste material is abundantly available in tropical regions in the world and it is used for operating boilers and furnaces. This burning of CSA results in a significant environmental pollution since large quantities of $\mathrm{CO}_{2}$ and methane are released. Under these circumstances, it can be used as a green reinforcement for production of Al-composites. The density of CSA has been recorded as $2.05 \mathrm{gm} / \mathrm{cm}^{3}$, while it contains elements like $\mathrm{SiO}_{2}$ (45.05\%), $\mathrm{Al}_{2} \mathrm{O}_{3}(15.6 \%), \mathrm{Fe}_{2} \mathrm{O}_{3}(12.4 \%)$ and $\mathrm{MgO}(16.2 \%)$ [36]. Therefore, development of AMCs reinforced with CSA has been found to be an economically viable option for reducing environmental emissions and disposal problems.

2.2f Bamboo leaf ash (BLA): The bamboo trees have been found to be available in large number in certain regions of the world. The leaves of these trees often litter in these regions that can be used to produce BLA for some economic purpose. The chemical composition of BLA includes ceramic oxides like $\mathrm{SiO}_{2}(75.9 \%), \mathrm{CaO}(7.47 \%), \mathrm{Al}_{2} \mathrm{O}_{3}$ $(3.5 \%), \mathrm{Fe}_{2} \mathrm{O}_{3}(1.22 \%)$ and $\mathrm{K}_{2} \mathrm{O}(5.62 \%)$ that indicate that it can be used in AMCs industry [37].

2.2g Graphite $(\mathrm{Gr})$ : Gr powder has been found to be quite valuable in industrial applications due to its self-lubricating properties under dry sliding conditions. Its density is of the order of $2 \mathrm{gm} / \mathrm{cm}^{3}$, which is much lower than that of the Al-alloys. Currently, it has been found to be a popular lubricant material that is used to improve the seizure resistance of the Al-composites under sliding wear conditions [15]. But, mechanism of the film formation that controls the wear behavior of these composites has to be clearly understood in case of HAMCs. It has been reported that addition of $\mathrm{Gr}$ can degrade mechanical properties of Al-composites and it may even have negative effect on the wear characteristics of these materials.

\section{Al/ceramics/industrial waste composites}

\subsection{Microstructure and mechanical properties}

During the casting process, the main objective is to avoid the formation of intermetallic phases in the composites specimens that can further degrade their interfacial properties. It has been noticed that $\mathrm{SiC}$ has tendency to react 
with the $\mathrm{Al}$ at a higher processing temperature to form intermediate compounds as given by following equation [38, 39]:

$$
3 \mathrm{SiC}+4 \mathrm{Al}=\mathrm{Al}_{4} \mathrm{C}_{3}+3 \mathrm{Si}
$$

The presence of aluminium carbide $\left(\mathrm{Al}_{3} \mathrm{C}_{4}\right)$ reduces the interfacial strength of the developed composites. In order to avoid this, addition of $\mathrm{SiO}_{2}$ into the Al-alloy has been found to be quite beneficial. David Raja Selvam et al [38] have found that incorporation of FA particles, which is a major source of $\mathrm{SiO}_{2}$, into Al6061-alloy prevents the formation of $\mathrm{Al}_{3} \mathrm{C}_{4}$ in the composite specimens. In this study, hybrid reinforcements ( $\mathrm{SiC}$ and $\mathrm{FA}$ ) were reinforced into the Al-alloy using stir casting route and microstructural analysis of developed composites revealed uniform dispersion of the particles within the composites. A clear interface between the reinforcement phase and the Al-alloy indicates that the formation of intermediate compounds was suppressed by addition of FA particles. It has been found that the Al-alloy reacts with the $\mathrm{Mg}$ present in the melt to form other compounds as per following equation:

$$
2 \mathrm{Al}+\mathrm{Mg}+2 \mathrm{SiO}_{2}=\mathrm{MgAl}_{2} \mathrm{O}_{4}+2 \mathrm{Si}
$$

Due to this, interfacial strength of the Al6061/SiC/FA composites was improved with addition of the FA particles. It has also been noticed that addition of hybrid reinforcements (10\% of $\mathrm{SiC}$ and $7.5 \%$ of $\mathrm{FA})$ improved the tensile strength and microhardness of the unreinforced Al6061-alloy by $23 \%$ and $16 \%$, respectively. This shows that the composites possess higher load bearing capacity due to presence of reinforcements [4]. Also, refinement of the grain size of the matrix alloy takes place due to addition of reinforcements that result in reduction in the ductility of the developed composites. The morphology of fractured surfaces indicates that failure of the alloy during tensile testing takes place due to formation of large-sized dimples (ductile fracture). On the other hand, the size of dimples has been reduced in the fractured surface of composite specimen that confirms the reduction in ductility of the hybrid composites.

Dwivedi et al [39] have developed A356/SiC/FA hybrid composites with different weight fractions of the reinforcement particles using electromagnetic stir casting (EMS) route. The EMS casting process has been found to be a good substitute to mechanical stir casting process to prevent contamination of the alloy melt and damage of the stirrer. The stirring parameters such as stirring speed, stirring time, stirring temperature, current and voltage were optimized to obtain adequate microstructural properties. The microstructure of the Al-composites at different compositions of the $\mathrm{SiC}$ and FA particles has been shown in figures 1(a-e). It has been observed in figures 1(a) and (b) that reinforcement particles are well-dispersed in the alloy matrix at a lower fraction (0 to $5 \mathrm{wt} . \%$ ) of FA particles. No evidence of pores has been observed in the microstructure of $\mathrm{Al} / 20 \% \mathrm{SiC}$ and $\mathrm{A} 356 / 15 \% \mathrm{SiC} / 5 \% \mathrm{FA}$ composites. This has been attributed to the optimum values of process parameters used for fabrication of composites. But, particle clusters can clearly be observed in figures 1(ce) for $\mathrm{A} 356 / \mathrm{SiC} / \mathrm{FA}$ composites at a higher FA fraction i.e., greater than $5 \mathrm{wt} \%$. This has been attributed to the lower density of FA particles that leads to formation of pores in the composites. Further, no signs of interfacial reaction between the matrix and reinforcement have been observed in the composite specimens. It has also been found that the mechanical properties of the composites are improved in comparison to the base alloy in as-cast and heat-treated conditions.

The variations in the tensile strength of $\mathrm{A} 356 / \mathrm{SiC} / \mathrm{FA}$ hybrid composites with respect to reinforcement ratio have been shown in figure 2 and it has been found that the addition of hybrid reinforcements ( $\mathrm{SiC}$ and $\mathrm{FA}$ ) results in significant work hardening of the composites in as-cast and heat-treated conditions during the tensile test. The work hardening is increased with increase in SiC fraction, while it reduces with increase in FA fraction beyond $5 \mathrm{wt} . \%$. Actually, increase in FA percentage beyond 5 wt.\% results in particle clustering in the composites that further increases the brittleness of the hybrid composites. Therefore, the strength of hybrid composites increases with 5 wt.\% addition of FA particles. If the FA percentage is increased from $5 \mathrm{wt} . \%$ to $20 \mathrm{wt} \%$, tensile strength of the hybrid composites is degraded due to an increase in the porosity as indicated in the microstructure of the hybrid composites. The tensile strength of heat-treated A356/15\%SiC/5\%FA composite has been found to be $12 \%$ higher in comparison to as-cast $\mathrm{A} 356 / 15 \% \mathrm{SiC} / 5 \% \mathrm{FA}$ composite. This is due to improvement in the distribution of the particles under heat treated conditions as indicated in the previous studies [40]. Similar trends have been obtained regarding variations in the other mechanical properties such as hardness, impact strength and fatigue strength of the hybrid composites i.e., A356/15\%SiC/5\%FA composites possess superior mechanical properties in as-cast and heat-treated conditions. The density of the hybrid composites is reduced linearly with an increase in the reinforcement fraction of FA particles. This is due to the lower density of FA particles in comparison to the Al-alloy and the SiC particles. Further, porosity of hybrid composites is reduced with an increase in FA fraction up to $5 \mathrm{wt} \%$ followed by an increasing trend. This increase in porosity of the hybrid composites at a higher FA percentage is due to the presence of particle clusters that leads to inhomogeneous structure of the composites. As far as the specific strength (U.T.S./density) is concerned, it has been found to be maximum at a FA fraction of $20 \mathrm{wt} \%$ due to lower density of the FA particles. In contrast, the thermal expansion has been found to be lowest at a FA fraction of $20 \mathrm{wt} \%$. But, $\mathrm{Al} / 20 \% \mathrm{FA}$ composites are not recommended for use due to degradation of mechanical properties at a higher fraction of FA particles. 


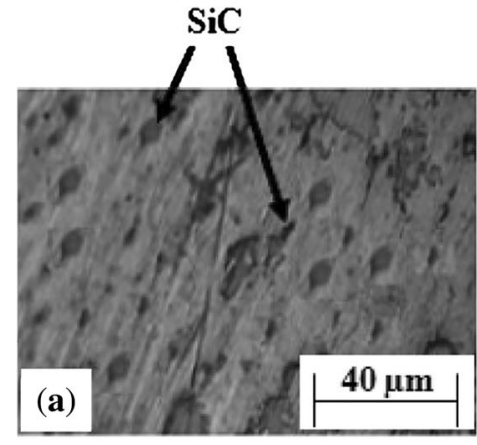

Sample No.1 A356 $+20 \%$ SiC $+0 \%$ Fly ash

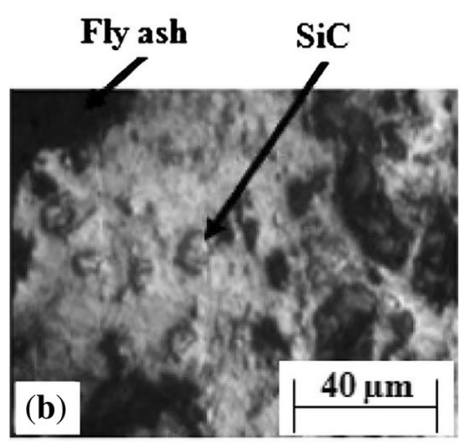

Sample No.2 A356+15\% $\mathrm{SiC}+5 \%$ Fly ash

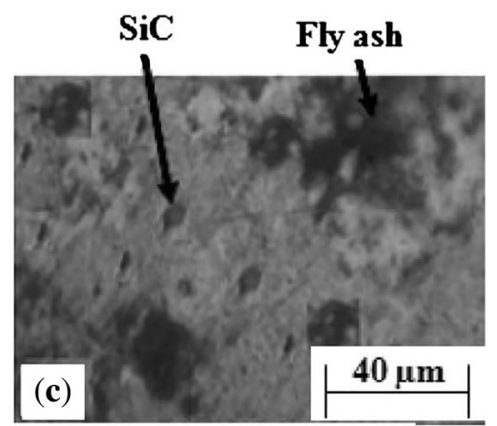

Sample No.3 A356 $+10 \% \mathrm{SiC}+10 \%$ Fly ash
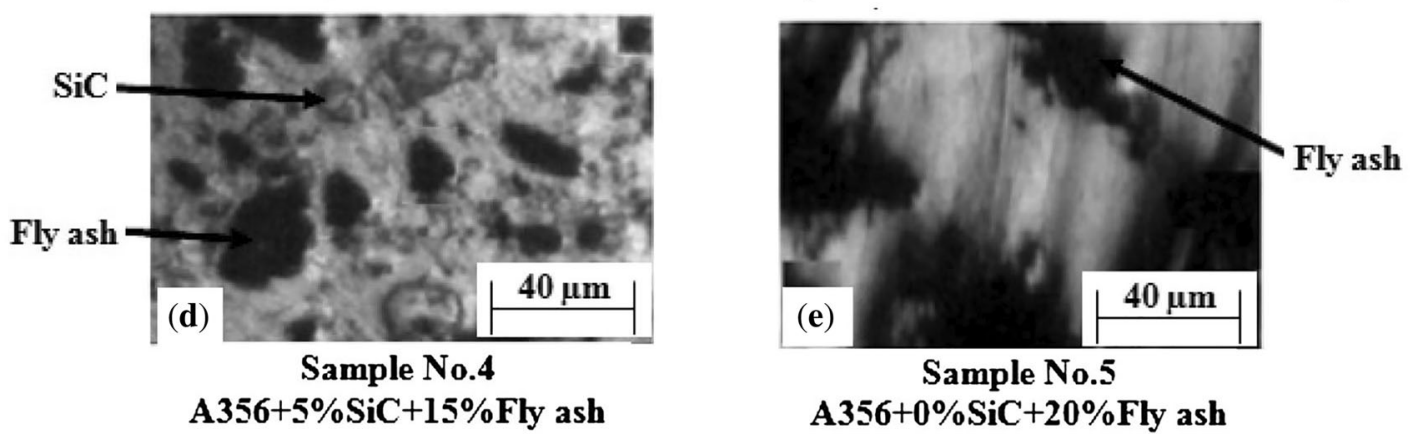

Figure 1. (a-e) Optical micrograph of A356/SiC/FA hybrid metal matrix composite at different percentage of reinforcements [39]. Reproduced with permission of Springer-2015.

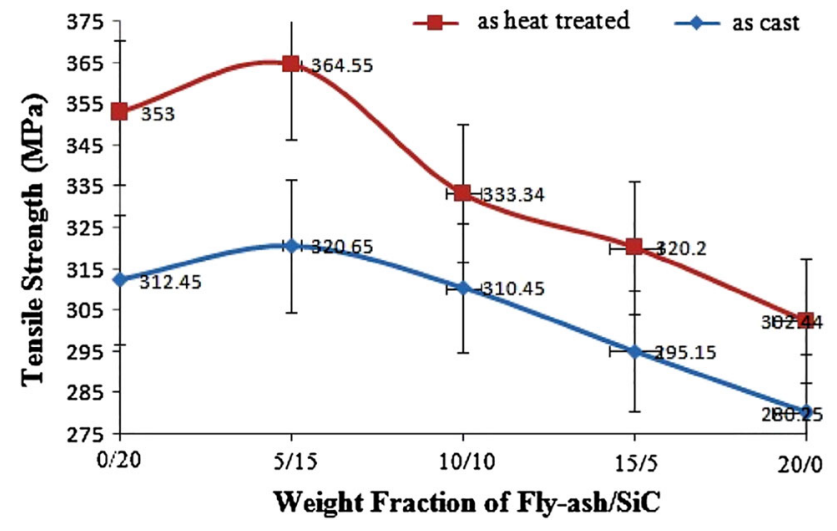

Figure 2. Variations in the tensile strength with respect to reinforcement ratio [39]. Reproduced with permission of Springer2015.

Singh and Chauhan [41] have developed Al2024/5\% SiC/ (5-20\%)RM hybrid composites using optimum process parameters in stir casting technique. It has been noticed that the reinforcement particles and the molten alloy have different densities due to which the vertical movement of particles may take place during casting process. Therefore, the developed composites are no more homogeneous and particle clusters/defects are present in the composite casting. In order to avoid these defects, reinforcement particles have been incorporated into the alloy in a semi-solid state. This increases the viscosity of the molten alloy that further reduces relative movements of the particles in the matrix. This results in a nearly homogeneous structure of the composites. The optimum value of casting temperature in this study has been found to be $650^{\circ} \mathrm{C}$. Further, it has been revealed that distribution of the reinforcement particles improves with an increase in stirring time. In this study, optimum values of stirring time and speed have been found to be $30 \mathrm{~min}$ and $600 \mathrm{rpm}$, respectively. The results of the study indicates that the hybrid composites exhibit good interfacial and dispersion properties that are prerequisites for obtaining superior mechanical strength of the composite specimens. Further, elements such as $\mathrm{Al}, \mathrm{C}, \mathrm{O}, \mathrm{Mg}, \mathrm{Cu}, \mathrm{Ca}$, $\mathrm{Si}$, etc. were also detected in the EDS analysis of the composite specimens. The density of the composites has been found to decrease (from $2.711 \mathrm{gm} / \mathrm{cm}^{3}$ to $2.641 \mathrm{gm} / \mathrm{cm}^{3}$ ) with an increase in RM wt.\% from (5 wt.\% to 10 wt.\%) followed by an increasing trend (up to $20 \mathrm{wt} . \%$ of RM particles). This has been attributed to the variations in the porosity within the composites that are further dependent on the processing conditions, particle size and the casting defects. In the experimental results, it has been found that RM fraction (5-20 wt.\%) has highest influence on the tensile strength response of the composites followed by ageing time $(0-24 \mathrm{~h})$. The size of RM particles $(37-125 \mu \mathrm{m})$ has been found to exhibit insignificant influence on the strength of the composites. Figure 3 shows the mean effect plots for $\mathrm{S} / \mathrm{N}$ ratio for tensile strength of the hybrid composites and it has been observed that the strength is increased with 


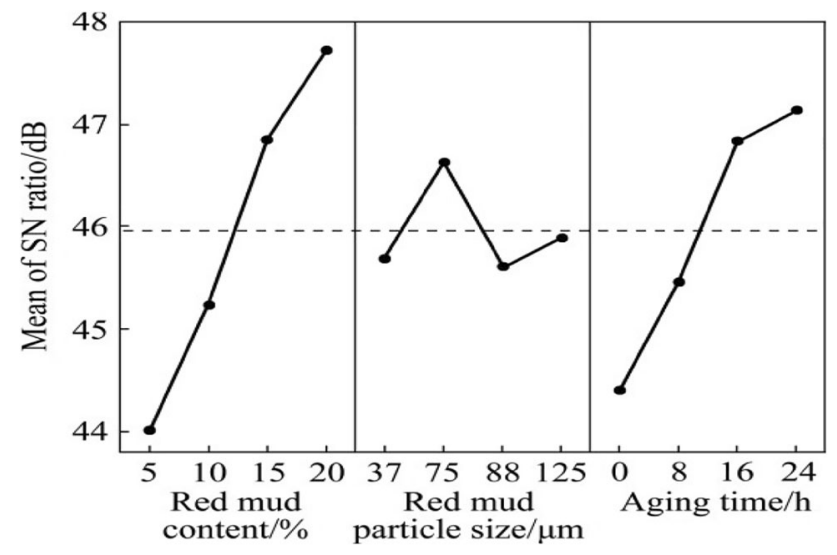

Figure 3. Mean effect plots for $\mathrm{S} / \mathrm{N}$ ratio for tensile strength response (larger the better) [41]. Reproduced with permission of Elsevier-2017.

increasing wt.\% of RM particles the ageing time. This is due to increased interfacial area between the reinforcement and matrix phase under these conditions [4]. The failure of the composites during tensile loading occurred due to particle debonding with significant shear flow of the fractured surface. A significant shear flow has been observed at a higher RM fraction that is an indication of the reduction in the brittleness in hybrid composites. A mathematical model regarding the influence of parameters was also developed in this study that was verified by conducting a confirmation experiment and analysis of fractured surfaces. The tensile strength of the composite was $34 \%$ higher in comparison to Al-alloy under optimized conditions of RM wt.\%, particle size and ageing time.

Kumar and Megalingam [42] have developed Al6061 based hybrid composites containing 3 wt. $\%$ of $\mathrm{Al}_{2} \mathrm{O}_{3 \mathrm{p}}$ percentage, 3 wt. $\%$ of $\mathrm{Gr}_{\mathrm{p}}$ percentage and (3-11 wt.\%) of $\mathrm{RM}$ content using casting route. It has been noticed that the hardness of the Al6061 based composites is increased with addition of 3 wt. $\%$ of $\mathrm{Al}_{2} \mathrm{O}_{3}$ particles, while it reduces with an increase in reinforcement fraction of RM particles. Actually, RM particles are relatively soft material in comparison to ceramic phase and thus an increase in RM content reduces the hardness of $\mathrm{Al} / \mathrm{SiC} / \mathrm{RM}$ hybrid composites. These results are in-line with those obtained by Singh and Chauhan [43], who have observed that hardness of the Al2024/5\% $\mathrm{SiC} /(5-20 \%) \mathrm{RM}$ hybrid composites is reduced with an increase in the wt.\% of RM particles. But, impact strength of the hybrid composites is improved with addition of RM particles. The presence of hard phase reduces the toughness of the Al-composites, while addition of $\mathrm{RM}$ reinforcement reduces the tendency of $\mathrm{Al} / \mathrm{SiC} / \mathrm{RM}$ hybrid composites for crack nucleation and propagation. Further, an increase in ageing time results in improvement in hardness and impact strength of the hybrid composites due to precipitation of intermediate phases and improved distribution of the particles [40]. In this study, analysis of variance (ANOVA) has been used to evaluate influence of the multiple variables on mechanical properties of A12024/ $\mathrm{SiC} / \mathrm{RM}$ hybrid composites. The statistical analysis has been performed for a confidence level of $95 \%$ and parametric contributions have been estimated by dividing the sum of squares for each parameter with total sum of squares. The adequacy of the developed models has been checked by evaluating the value of $\mathrm{R}^{2}$ that represents the degree of variation and fit of a model. The results of ANOVA indicate that ageing time is the most influential parameter (with a contribution of $81 \%$ ) as far as the hardness of the hybrid composites is concerned, while RM wt.\% has highest influence on the impact strength (with a contribution of $55 \%$ ). The values of $\mathrm{R}^{2}$ for the developed models have been found to be greater than $95 \%$ that confirms the adequacy of the developed ANOVA models. The optimum combinations of the selected parameters have been obtained by drawing 3-dimensional response plots. The results of confirmation experiments show that hardness and impact energy of Al2024 alloy are improved by $97.5 \%$ and $25 \%$, respectively by incorporation of hybrid reinforcements under optimized conditions of reinforcement factors and ageing time.

Wang [10] have developed in-situ $\mathrm{Al}_{2} \mathrm{O}_{3} / \mathrm{SiO}_{2 \mathrm{p}} / \mathrm{Al}$ composites using ZTS via stir casting route. It has been noticed that the distribution and wettability of the particles are improved under optimized process conditions i.e., feed rate of $10 \mathrm{~g} / \mathrm{min}$, preheating the particles at $700{ }^{\circ} \mathrm{C}$ for $1 \mathrm{~h}$, and stirring time of $10 \mathrm{~min}$. The microstructure of the hybrid composites at different fraction of reinforcement particles has been shown in figure 4 . The pulling out of the particles (voids marked by arrows) has been observed in figures 4(a) and (b). At a higher reinforcement percentage, particle distribution has been reduced due to increase in fluidity of the molten alloy as presented in figure 4(c). The elemental analysis of the developed composites has confirmed the presence of $\mathrm{Al}_{2} \mathrm{SiO}_{5}, \mathrm{Al}_{2} \mathrm{O}_{3}, \mathrm{Si}$ and duplex phase. The $\mathrm{SiO}_{2} / \mathrm{Al}$ in-situ reaction was confirmed by thermal cooling curves, while presence of $\mathrm{Al}_{2} \mathrm{O}_{3}$ particles was confirmed by scanning electron micrographic (SEM) and energy dispersive spectrum (EDS) analysis. The increase in the reinforcement fraction increased the hardness and the strength of the hybrid composites while the percent elongation was reduced. The tensile strength of the composite specimen was found to be maximum at a reinforcement fraction of $7 \mathrm{wt} . \%$ that was $74.4 \%$ higher than that of unreinforced alloy.

The analysis of failure mechanisms of Al-alloy shown in figure 5(a) indicate that $\mathrm{Al}$ fails with significant plastic deformation due to which a large number of dimples are formed on the fractured surface. Figure 5(b) shows that the particle fracture takes place in the composite specimens and brittle fracture is predominant failure mechanism with less area of cavities. This may be due to the fact that composites with a lower reinforcement's fraction cannot resist plastic deformation arising from stress concentration due to the 


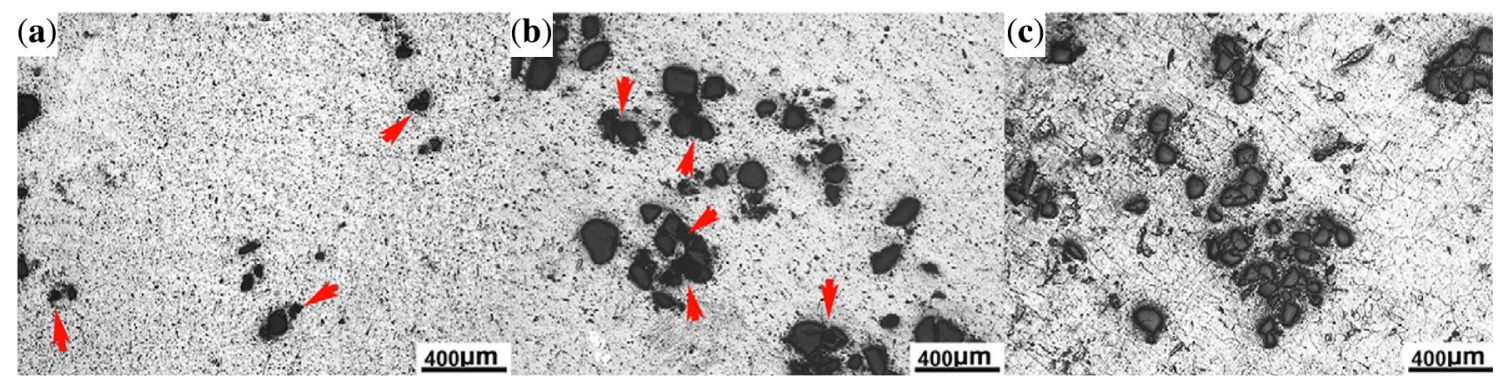

Figure 4. SEM images of $\mathrm{Al}_{2} \mathrm{O}_{3} / \mathrm{SiO}_{2 \mathrm{p}}$ composites at a reinforcement's fraction of (a) 1 wt. \%, (b) 3 wt.\%, (c) 5 wt.\% [10]. Reproduced with permission of Elsevier-2016.

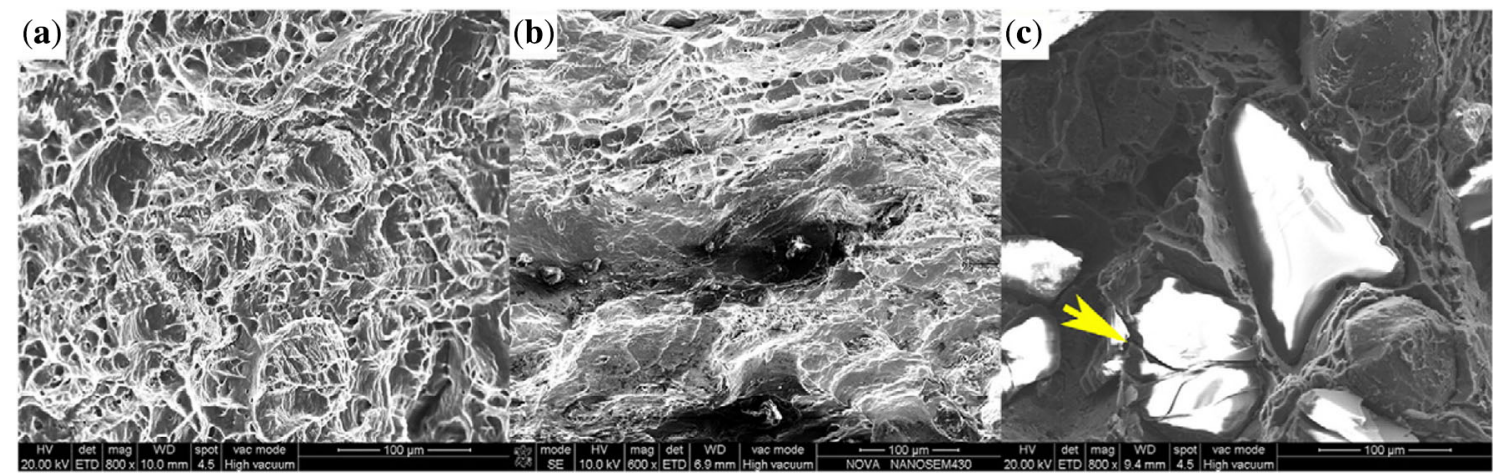

Figure 5. Fracture pattern of (a) the pure Al, and the composites at (b) 7 wt.\% and (c) 9 wt.\% [10]. Reproduced with permission of Elsevier-2016.

presence of defects. On the other hand, debonding of the particles and cracking phenomenon are predominant failure mechanisms in the composite specimens at a higher percentage of reinforcement particles. This has been attributed to the increased tendency of particle agglomeration of the composite specimens at a higher reinforcement percentage as shown in figure $5(\mathrm{c})$.

\subsection{Wear properties}

Kurapati et al [44] have successfully fabricated A12024/ $\mathrm{x} \% \mathrm{SiC} / \mathrm{x} \% \mathrm{FA}(\mathrm{x}=2.5-7.5 \%)$ composites using stir casting technique it has been revealed that the hybrid composites exhibit nearly homogeneous structure. The wear tests have been conducted on pin-on-disc apparatus under dry sliding conditions. It has also been noticed that A12024/SiC/FA composite specimens possess superior wear resistance as compared to unreinforced Al2024 alloy. The applied load has been found to be the most influential parameter followed by sliding time and reinforcement fraction. It has been found that plastic deformation of the hybrid composites is increased with an increase in sliding time and applied load. This has been attributed to the increased metallic contact between the rubbing surfaces that leads to increase in temperature and pressure at the interface. But, surface deformation of the composite specimens is reduced to a significant extent with increasing reinforcement fraction (up to $15 \mathrm{wt} . \%$ ). This has been attributed to increased hardness and abrasion resistance of the composites with an increase in reinforcement fraction that reduces the wear rate under different conditions of sliding time and applied load. Figure 6 shows the contour plots for wear (W) of the hybrid composites under different values of the investigated parameters. It has been noticed that the lower value of $\mathrm{W}$ is related to a higher value of reinforcement content $(\mathrm{R})$ and lower values of applied load (L) and sliding time (T). The experimental results have been correlated with the morphological analysis of the worn surfaces. It has been noticed that the worn surface of $\mathrm{Al} / 5 \% \mathrm{SiC} / 5 \% \mathrm{FA}$ composites at a load of $0.5 \mathrm{~N}$ and sliding time of $45 \mathrm{~min}$ consists of various zones like wear track, rupture of surface film, particle pull out and wear debris. Further, deep groves were observed on the worn surface of the hybrid composites. On the other hand, the worn surface of $\mathrm{Al} / 7.5 \% \mathrm{SiC} /$ $7.5 \% \mathrm{FA}$ composites has been found to be relatively smooth under same sliding conditions. Various zones like fine cracks and abrasive grooves have also been observed on the wear surface. The study indicates that the plastic strain and sub-surface deformation of the composites increases with increasing sliding time and applied load and this phenomenon has been considerably reduced with addition of hybrid reinforcements. 

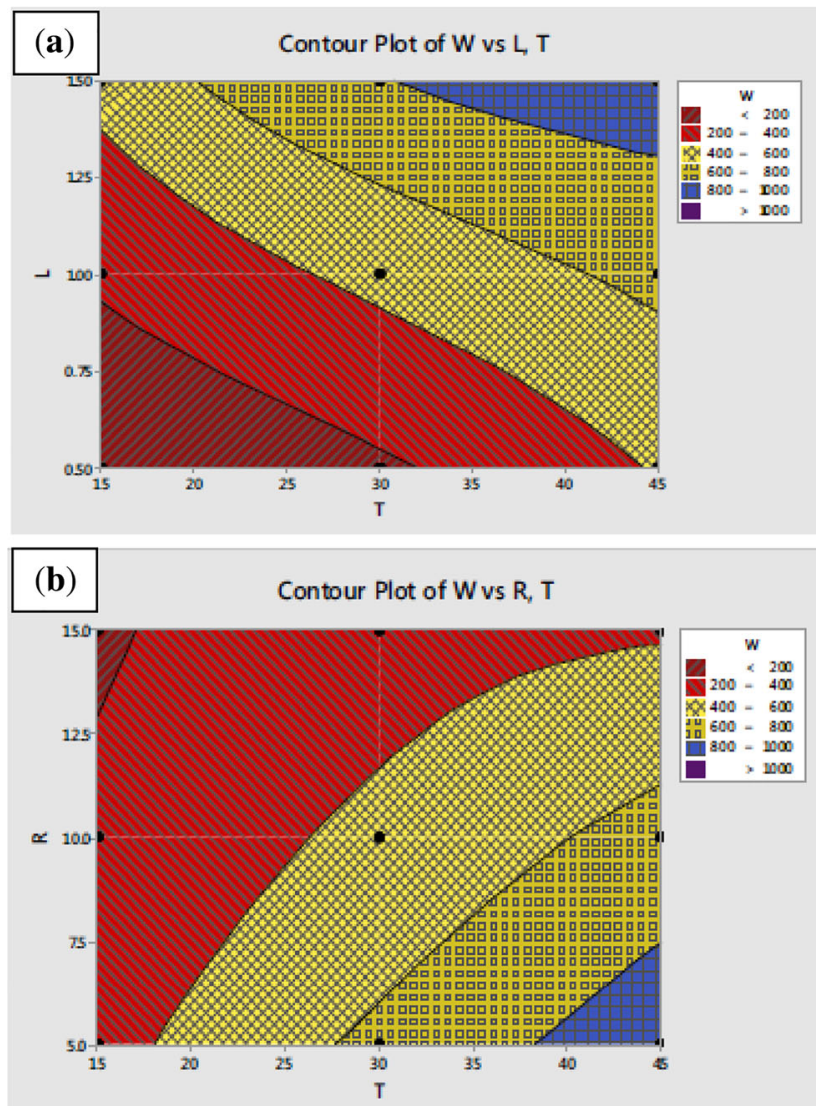

Figure 6. Contour plots of wear of the A12024/SiC/FA composites with respect to (a) $\mathrm{R}$ and $\mathrm{T}$, (b) $\mathrm{L}$ and $\mathrm{R}$ ( $\mathrm{T}=$ Sliding time (min), $\mathrm{L}=$ load (kgf) and $\mathrm{R}=$ Reinforcement fraction (wt.\%) [44]. Reproduced with permission of Springer-2018.

Kumar and Megalingam [42] have noticed that inclusion of RM particles improves abrasion resistance of the $\mathrm{Al} 6061 / \mathrm{Al}_{2} \mathrm{O}_{3} / \mathrm{Gr}$ hybrid composites irrespective of the magnitude of applied load. The wear tests were conducted on a pin-on-disc monitor and EN 32 steel disc was used as a counterface material. In this study, the wear rate of the hybrid composites increases with an increase in the magnitude of applied load, sliding distance and velocity due to increased adhesive wear of the composite specimens. But, an increase in reinforcement fraction of $\mathrm{RM}$ particles

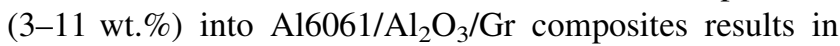
reduction in specific wear rate of the hybrid composites. The analysis of the worn surfaces of the hybrid composites confirms that the addition of RM particles delays the transition of the wear mechanism from mild to severe wear even under severe sliding conditions. Under same sliding conditions, the wear mechanisms changed from severe to mild due to increased RM content. In case of 3 and 7 wt.\% reinforced composites, both abrasive and adhesive wear mechanisms were observed due to particle ejection and ploughing of the wear surface. But, wear mechanism changed from adhesive to abrasive for $11 \mathrm{wt} . \% \mathrm{RM}$ reinforced composites. The increase in the wear performance of the hybrid composites occurs due to presence of tribolayers between the rubbing surfaces that reduced the deformation of the hybrid composites [45]. Therefore, HAMCs reinforced with 11 wt.\% of RM percentage were recommended as a substitute materials for brake rotor applications in automobiles.

\section{Al/ceramics/agro-waste ashes composites}

\subsection{Microstructure and mechanical properties}

Prasad et al [46] have observed the characteristics of hybrid composites developed by reinforcing $\mathrm{SiC}(0-8 \mathrm{wt} . \%)$ and RHA (0-8 wt.\%) particles in equal proportions into A356 alloy. Figure 7(a) shows the microstructure of the developed composites indicating that the reinforcement particulates are adequately dispersed within the Al-alloy. Also, no evidence of chemical reaction between the reinforcement and the matrix phase has been observed. A good interfacial bonding between two phases of the matrix has been observed in figure 7(b) that is an indication of superior mechanical properties of hybrid composites. Further, Prasad et al [46] have also investigated the variations in the mechanical properties of hybrid composites with respect to reinforcement ratio. It has been noticed that tensile strength and hardness of the hybrid composites increase with increasing reinforcement fraction, while density, porosity and ductility are reduced. The tensile strength of the hybrid composites is increased by about $35 \%$ with an increase in reinforcement fraction of each constituent by $8 \mathrm{wt} . \%$. The improvement in the strength of the hybrid composites has been attributed to the thermal mismatch between the two phases of the composites. Actually, coefficients of thermal expansion (CTE) for A356, SiC and RHA have been recorded as $21.4 \times 10^{-6} /{ }^{\circ} \mathrm{C}, 4.3 \times 10^{-6} /{ }^{\circ} \mathrm{C}$ and $10.1 \times$ $10^{-6} /{ }^{\circ} \mathrm{C}$, respectively. Therefore, change in temperature during processing of the composites results in generation of thermal stresses that are released by formation of dislocations in the vicinity of the interface in order to fulfill geometric constraints. The density of dislocations generated in the composites can be predicted by using following relation:

$$
\rho=\frac{B \varepsilon V_{r}}{b d\left(1-V_{r}\right)}
$$

The empirical equation for dislocation density of hybrid composites can be written as following:

$$
\rho=\frac{B \varepsilon\left(V_{R H A}+V_{S i C}\right)}{b d\left\{1-\left(V_{R H A}+V_{S i C}\right)\right\}}
$$

where $B$ is a geometric constant that depends on the aspect ratio. Its value changes between 12 for equiaxed particulates and 4 for whisker-like particulate. $\varepsilon$ is the thermal 

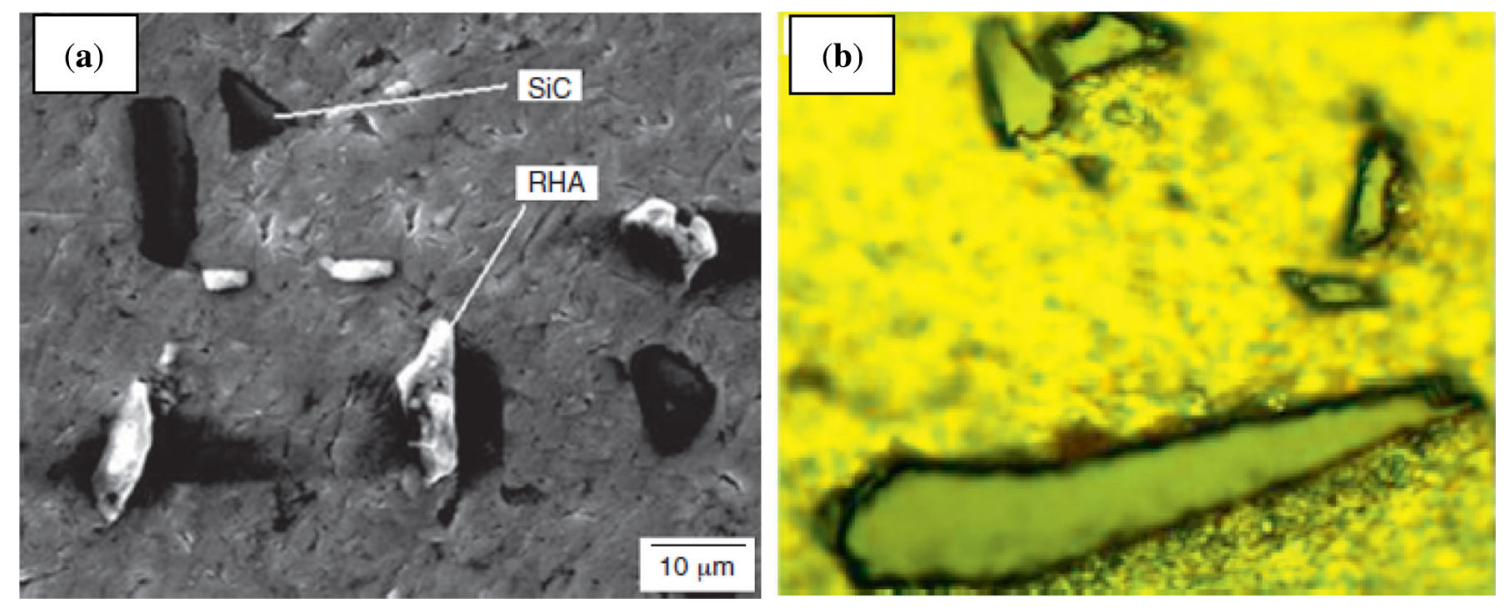

Figure 7. SEM image of (a) A356/SiC/RHA hybrid composite, (b) at the interface [46]. Reproduced with permission from copyright owner.

mismatch strain i.e., the product of temperature change $(d T)$ during solidification of the composites and CTE difference $(d \alpha)$ between reinforcement and matrix, $V_{r}$ is the volume fraction of the reinforcement, $b$ is the Burgers vector, and $d$ is the average grain diameter of reinforcements. Although, value of CTE is relatively difficult to evaluate since it is influenced by various factors like internal structure of the composite and plasticity, but its value can be evaluated by various thermo-elastic energy principles such as Kerner and Turner models. The value of CTE for the hybrid composites has been obtained by simple rule of mixtures:

$$
\alpha_{c}=\alpha_{m} V_{m}+\alpha_{R H A} V_{R H A}+\alpha_{S i C} V_{S i C}
$$

where $V$ is the volume fraction of the constituent, and $\alpha$ is CTE of the constituent of composites. The subscripts $c$, and $m$ refer to the composite, particle and matrix, respectively. $K$ is the bulk modulus of the constituents of the composite, which can be evaluated from the simple relations between elastic constants. It has been noticed that CTE is decreased from $21.4 \times 10^{-6} /{ }^{\circ} \mathrm{C}$ to $15.06 \times 10^{-6} /{ }^{\circ} \mathrm{C}$, while the dislocation density is increased to a level of $30.82 \times 10^{11}$ with increase in the reinforcement ratio (up to $8 \mathrm{wt} \%$ of each constituent) in the A356/RHA/SiC hybrid composites. The strengthening effect due to the increase in the dislocation density generated by the differential CTE can be evaluated by following equation:

$$
\sigma=k G b\left(\rho^{\frac{1}{2}}\right)
$$

where $\sigma$ is the yield strength improvement due to increase in dislocation density, $k$ is a constant with value varying between $0.5-1.0, G$ is shear modulus and $b$ is the Berger vector. It has also be revealed that an increase in reinforcement percentage also improves the ageing kinetics of the hybrid composites i.e., the time required for attaining peak hardness in composites during ageing process has been reduced with an increase in the reinforcement content. This has been attributed to increase in the dislocation density (as discussed above) in the hybrid composites with increase in reinforcement ratio that further accelerates diffusion of the ageing elements.

Aleneme et al [47] have developed $\mathrm{Al}-\mathrm{Mg}-\mathrm{Si}$ matrix hybrid composites reinforced with RHA and $\mathrm{Al}_{2} \mathrm{O}_{3}$ in different weight fractions (reinforcement ratios of $0: 10,2: 8$, $3: 7$ and 4:6) so as to maintain a reinforcement fraction of $10 \mathrm{wt} . \%$. The SEM and EDS analysis of the developed composites was conducted to confirm successful incorporation of the reinforcements. It has been found that hybrid composite containing $4 \mathrm{wt} . \%$ of RHA contents exhibit better dispersion of particulates in comparison to the single reinforced ( $\mathrm{Al}-\mathrm{Mg}-\mathrm{Si} / 10 \mathrm{wt} . \% \mathrm{Al}_{2} \mathrm{O}_{3}$ ) composite due to lower density of RHA $\left(0.31 \mathrm{~g} / \mathrm{cm}^{3}\right)$ in comparison with $\mathrm{Al}_{2} \mathrm{O}_{3}\left(3.18 \mathrm{~g} / \mathrm{cm}^{3}\right)$. The variations in the properties of the $\mathrm{Al} / \mathrm{SiC} / \mathrm{RHA}$ composites with respect to reinforcement compositions have also been studied by Alaneme et al [47]. It has been observed that the density and porosity of the hybrid composites are reduced with an increase in the wt.\% of RHA particles. Further, tensile strength and hardness of hybrid $\mathrm{Al} / \mathrm{Al}_{2} \mathrm{O}_{3} / \mathrm{RHA}$ composites are slightly decreased with increasing RHA percentage. The decrease in tensile strength for the hybrid composites containing $2 \%, 3 \%$ and 4 wt. $\%$ of RHA reinforcement has been observed as $3.7 \%$, $8 \%$ and $13 \%$, respectively compared with single reinforced (Al-Mg-Si/10 wt. $\% \mathrm{Al}_{2} \mathrm{O}_{3}$ ) composite (with tensile strength of $125.5 \mathrm{MPa}$ ). Similarly, maximum reduction of $11 \%$ in the hardness has been observed for hybrid composites with 4 wt.\% of RHA content compared with ceramic reinforced composites $(67 \mathrm{BHN})$. The slight decrease in strength and hardness of hybrid composites may be attributed to the reduction in the contribution of the direct strengthening effect (load carrying capacity) due to increased percentage of soft RHA particles. The major constituent of RHA is $\mathrm{SiO}_{2}$ that has elastic modulus similar to that of aluminum. 
Therefore, load carrying capacity of the composites is dependent in the percentage of $\mathrm{Al}_{2} \mathrm{O}_{3}$ rather than the RHA. However, fracture toughness, percent elongation and specific strength of hybrid composites with RHA particles have been found to be higher than that of $\mathrm{Al} / \mathrm{Al}_{2} \mathrm{O}_{3}$ composites. The mechanisms of fracture of the Al-composites such as particle cracking and interfacial debonding have been reported by various authors [41, 43]. In present case, improvement in the fracture toughness of the hybrid composites with increase in the RHA fraction has been attributed to the presence of softer $\mathrm{SiO}_{2}$ phase. It has been noted that the ceramic particulates are brittle in nature and have poor resistance to rapid crack propagation. Similar type of results have been obtained in another study conducted by Alaneme et al [48], who have found that addition of BLA as a secondary reinforcement does not deteriorate the mechanical properties of the $\mathrm{Al} / \mathrm{SiC} / \mathrm{BLA}$ hybrid composites. The results indicate that the hardness and strength of the hybrid composites increase with increasing wt.\% of BLA particle. On the other hand, specific strength and fracture toughness of hybrid composites has been found to be comparable to $\mathrm{Al}_{2} \mathrm{O}_{3}$ reinforced Al-composites.

Siva Sankara Raju et al [49] have studied the mechanical behaviour of Al-1100 based hybrid composites containing using $\mathrm{Al}_{2} \mathrm{O}_{3}, \mathrm{CSA}$ and $\mathrm{Gr}$ particles fabricated by liquid metallurgy route. Five types of composites containing equivalent fractions of $\mathrm{Al}_{2} \mathrm{O}_{3}, \mathrm{CSA}$ and $\mathrm{Gr}$ were fabricated and their mechanical properties were evaluated as shown in table 1. It has been observed that addition of $\mathrm{Al}_{2} \mathrm{O}_{3}$ particles increases the density of resultant composites, while addition of CSA and Gr particles results in reduction in the density values. The reduced density is helpful in enhancing the specific strength of the composites as indicated in the results presented in table 1. Among all compositions, Al/ CSA composite possess least density due to light weight of CSA particles. If we analyze the hardness values of the composites, it can be observed that all the composites possess superior hardness values in comparison to the unreinforced alloy. This is due to the increased hardness of reinforcement particles distributed within the soft matrix. Here again, Al-CSA composites possess superior BHN value followed by $\mathrm{Al} / \mathrm{Al}_{2} \mathrm{O}_{3}$ composite. The addition of $\mathrm{Gr}$ reduces the hardness value (as indicated in table 1) due to increase in the porosity in the resultant composites ( $\mathrm{Al} /$ $\mathrm{Al}_{2} \mathrm{O}_{3} / \mathrm{Gr}$ and $\mathrm{Al} / \mathrm{CSA} / \mathrm{Gr}$ composites). The Gr-content in this study has been taken as $3 \%$ so as to control the porosity level while improving machinability of the composites. Here, Al/CSA/Gr composites have been found to possess tensile strength lower than that of Al/CSA composites due to increased toughness value as indicated in the stress-strain diagram in this study. The percentage elongation of the composites gives the level of brittleness of the composites that is minimum in the $\mathrm{Al} / \mathrm{Al}_{2} \mathrm{O}_{3}$ composites and maximum in case of $\mathrm{Al} / \mathrm{CSA} / \mathrm{Gr}$ composite. These results have been verified by SEM analysis of the fractured surfaces of the composites. In case of Al/CSA/Gr composites, small-sized dimples with river-pattern have been observed on the surface fractured during tensile test that is an indication the highest toughness of these composites.

\subsection{Wear properties}

A large number of investigations have been carried regarding the wear properties of hybrid composites reinforced with ceramics and agro-waste ashes such as RHA. According to Prasad and Shobha [50], the Al356.2/x\% SiC/ $\mathrm{x} \%$ RHA ( $\mathrm{x}=0-8 \mathrm{wt} . \%$ ) hybrid composites exhibit higher wear resistance in comparison to the unreinforced alloy. In this case, wear tests have been conducted using CETR UMT-2 Tribometer at a load of $25 \mathrm{~N}$ for a time period of 1000 s. Prasad and Shobha [50] have also studied the variations in the weight loss of the unreinforced alloy and the composite specimens as a function of normal load have been shown in figure 8 . It has been found that wear loss is highest in case of alloy specimen under all conditions of load, while the hybrid composites containing $8 \mathrm{wt} \%$ of each reinforcement exhibit maximum wear resistance among all the specimens. It has also been noticed that an increase in the reinforcement ratio reduces the wear loss of the composite specimens irrespective of the magnitude of applied load. But, the wear loss is linearly increased with an increase in the magnitude of applied load due to increase in the penetration of the counterface into the wear surface. It has been reported that the dislocation density and load transfer capabilities of the hybrid composites are increased with increasing reinforcement ratio that further improves their abrasion resistance [40]. A steep increase in the wear loss of the alloy specimen was observed with an increase in the magnitude of applied load. The wear loss for A356.2/

Table 1. Mechanical properties of Al-1100 based composites with different compositions [49]. Reproduced with permission from Springer 2017.

\begin{tabular}{lccccc}
\hline Composition & Density $\left(\mathrm{gm} / \mathrm{cm}^{3}\right)$ & Tensile strength $\left(\mathrm{N} / \mathrm{mm}^{2}\right)$ & Elongation $(\%)$ & Hardness $(\mathrm{BHN})$ & Specific strength $(\mathrm{N}-\mathrm{mm} / \mathrm{kg})$ \\
\hline $\mathrm{Al}-1100$ & 2.72 & 104 & 21.91 & 28.30 & 43.40 \\
$\mathrm{Al} / \mathrm{Al}_{2} \mathrm{O}_{3}$ & 2.88 & 147 & 13.27 & 50.53 & 52.70 \\
$\mathrm{Al} / \mathrm{Al}_{2} \mathrm{O}_{3} / \mathrm{Gr}$ & 2.85 & 126 & 17.11 & 49.97 & 51.30 \\
$\mathrm{Al} / \mathrm{CSA}$ & 2.47 & 173 & 13.85 & 51.33 & 63.29 \\
$\mathrm{Al} / \mathrm{CSA} / \mathrm{Gr}$ & 2.50 & 154 & 18.23 & 50.42 & 60.40 \\
\hline
\end{tabular}




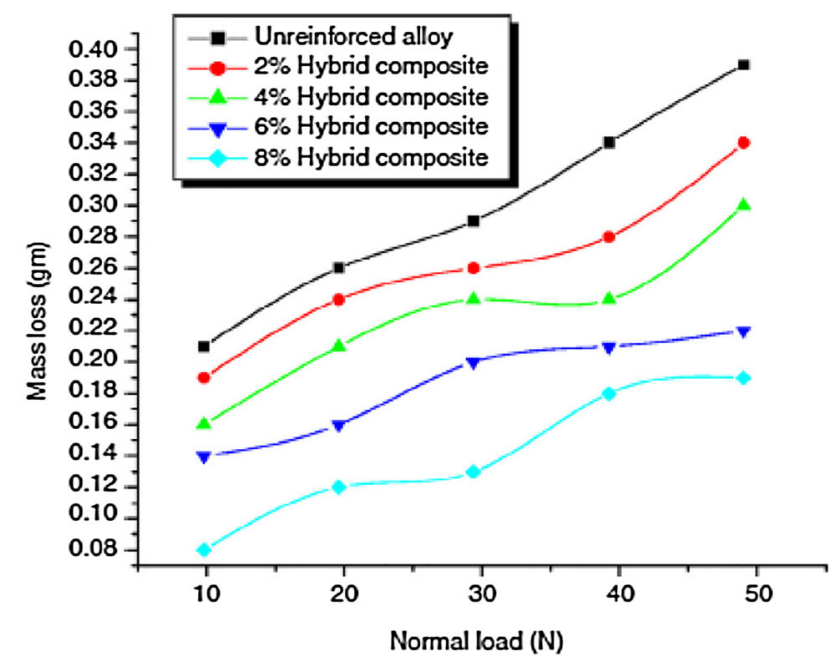

Figure 8. Mass loss vs \%age of hybrid reinforcement [50]. Reproduced with permission from copyright owner.

$8 \% \mathrm{SiC} / 8 \%$ RHA composites remains constant even under severe wear conditions $(40-50 \mathrm{~N})$. The results obtained have been verified by the morphological analysis of the worn surfaces. Figure 9(a) shows the worn surface of A356/2\% SiC/2\%RHA hybrid composites at a load of $49 \mathrm{~N}$. It has been observed that the wear surface is plastically deformed by the counerface. Figure 9 (b) shows that the plastic flow and delamination of the wear surface is reduced with an increase in the reinforcement content. According to Prasad and Shobha [50], a small cavity has also been the subsurface of the composites. This is an indication of the severe wear of the specimens under sliding wear conditions. But, delamination has been restricted to a smaller area of the worn surface for $\mathrm{Al} 356.2 / 8 \% \mathrm{SiC} / 8 \% \mathrm{RHA}$ composites as shown in figure 9(b). Here, shallow ridges and grooves are formed on the wear surface have been observed that is an indication of reduction in the plastic flow of the wear surface. This shows that the incorporation of hybrid reinforcements in equal proportions improves the wear resistance of the hybrid composites.
The results obtained are in agreement with those obtained by Alaneme et al [51] showing that use of RHA as a complementary reinforcement do not degrade the coefficient of friction and wear properties of the $\mathrm{Al} / \mathrm{SiC} / \mathrm{RHA}$ hybrid composites. In this study, Al-Mg-Si alloy was reinforced with RHA and $\mathrm{SiC}$ particles in different weight fractions $(0: 1,1: 3,1: 1,3: 1$, and 1:0) so as to maintain the reinforcement fractions as 5, 7.5 and $10 \mathrm{wt} \%$. The variations in the coefficient of friction of $5 \mathrm{wt} . \%$ reinforced $\mathrm{Al}-$ $\mathrm{Mg}-\mathrm{Si}$ composites with different weight ratios of RHA:SiC have been shown in figure 10(a). It has been observed that hybrid composite (B2) containing RHA:SiC weight ratio as 1:3 exhibits minimum coefficient of friction among all the specimens with 5 wt.\% of reinforcement phase. The other hybrid composition i.e., B3 and B4 with RHA:SiC weight ratios of $1: 1$ and $3: 1$, respectively possess friction coefficient comparable to single reinforced composites i.e., $\mathrm{Al} /$ $\mathrm{SiC}$ (B1) and Al/RHA (B5) composites. In case of $10 \mathrm{wt} . \%$ reinforced $\mathrm{Al}-\mathrm{Mg}$-Si composites as shown in figure 10(b), the hybrid composite (D4 with RHA:SiC ratio of 3:1) and single reinforced Al-Mg-Si/RHA composites have lower values of coefficient of friction in comparison to other composites (D1, D2 and D3). This has been attributed to the higher percentage of RHA particles that improves the wear resistance of the hybrid composites. This indicates that addition of RHA as a secondary reinforcement does not degrade the wear performance of the $\mathrm{Al}-\mathrm{Mg}-\mathrm{Si}$ based composites. The unreinforced alloy exhibit highest coefficient of friction since the hard asperities of the counterface leads to considerable material loss due to ploughing and microcutting of the wear surface during sliding conditions. It has been noticed the adhesive wear mechanism is responsible for the increased value of friction coefficient of the composites. In case of hybrid composites, abrasive wear has been found to predominant wear mechanism, while adhesion of the wear debris has been observed in the single reinforced composites and the unreinforced alloy.

In contradiction to above results, Alaneme and Olubambi [52] have found that the composites developed by
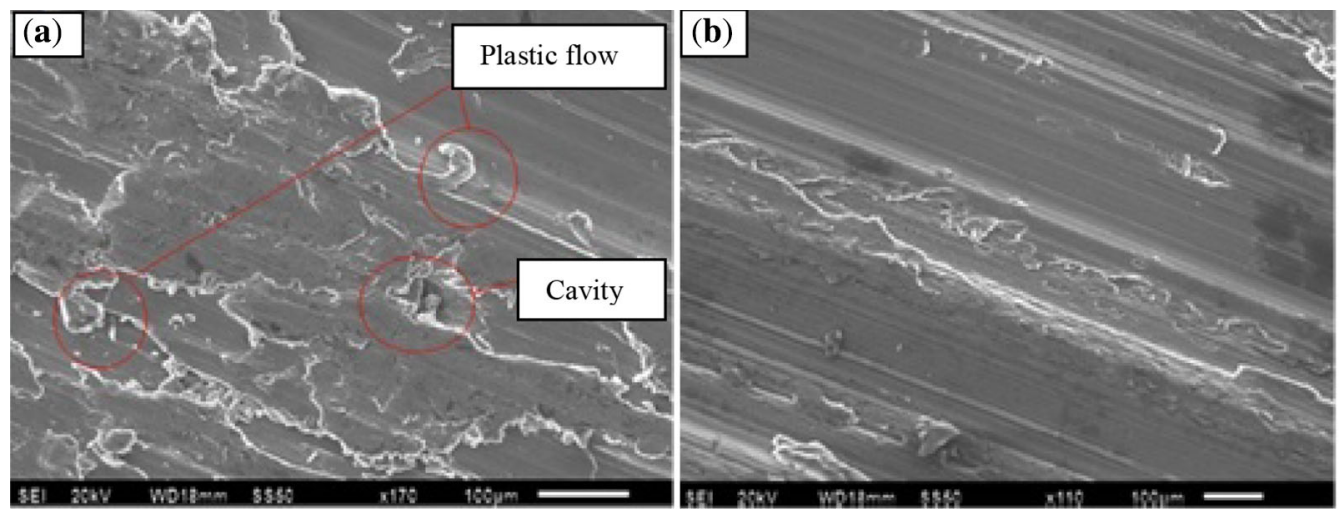

Figure 9. Worn surface morphology of (a) A356.2/2\%RHA/2\%SiC and (b) A/8\%RHA/8\%SiC composites, at a load of $49 \mathrm{~N}$ [50]. Reproduced with permission from copyright owner. 


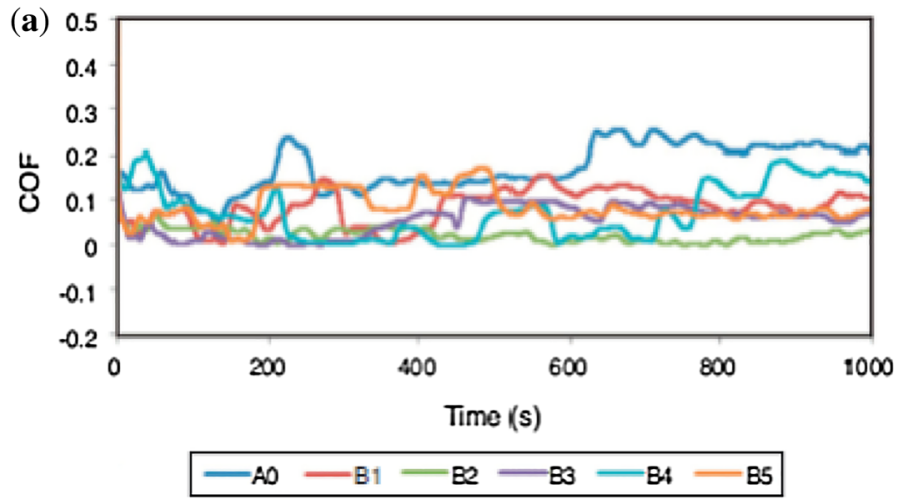

$\begin{array}{ll}\begin{array}{l}\text { Composite } \\ \text { designation }\end{array} & \begin{array}{l}\text { weight ratio } \\ \text { of RHA:SiC }\end{array} \\ \text { A0 } & 0 \\ \text { B1 } & 0: 1 \\ \text { B2 } & 1: 3 \\ \text { B3 } & 1: 1 \\ \text { B4 } & 3: 1 \\ \text { B5 } & 1: 0\end{array}$

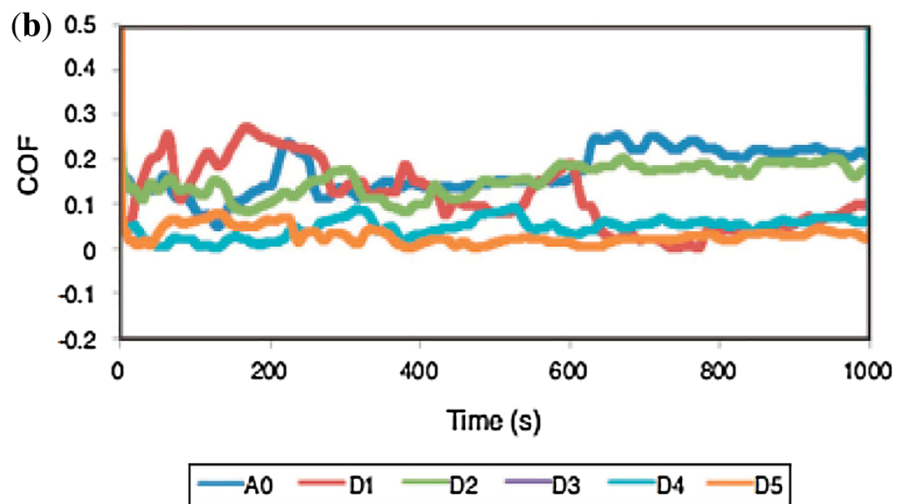

Composite
designation
A0
D1
D2
D3
D4
D5

weight ratio
of RHA:SiC
0
$0: 1$
$1: 3$
$1: 1$
$3: 1$
$1: 0$

Figure 10. Variations in the friction coefficient with time for Al-Mg-Si composites containing RHA-SiC reinforcement of (a) 5 wt.\% and (b) 10 wt.\% [51]. Reproduced with permission from copyright owner.

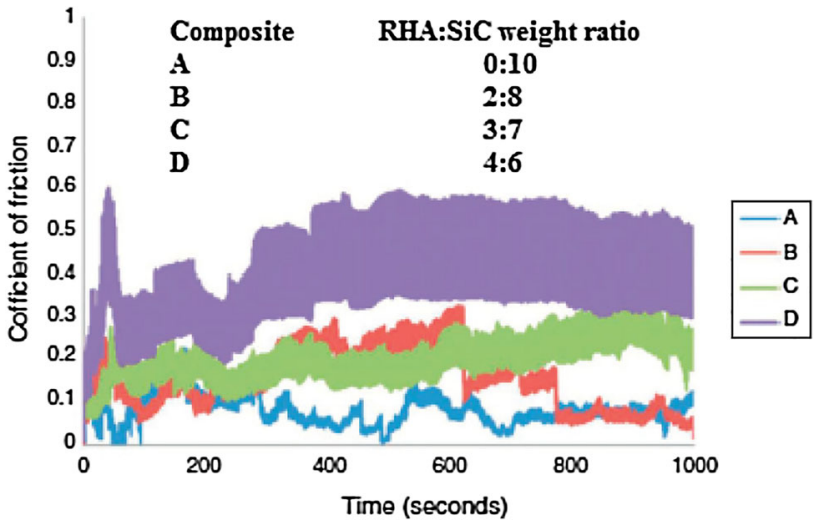

Figure 11. Variations in the friction coefficient of hybrid Al-Mg$\mathrm{Si} / 10 \%\left(\mathrm{Al}_{2} \mathrm{O}_{3}+\mathrm{RHA}\right)$ composite and $\mathrm{Al} / 10 \% \mathrm{Al}_{2} \mathrm{O}_{3}$ composites with respect to time [52]. Reproduced with permission from copyright owner.

reinforcing Al-matrix with 10 wt. $\% \quad \mathrm{Al}_{2} \mathrm{O}_{3}$ exhibit lower wear loss as compared to $\mathrm{Al}-\mathrm{Mg}-\mathrm{Si} / \mathrm{Al}_{2} \mathrm{O}_{3} / \mathrm{RHA}$ hybrid composites. The variations in the friction coefficient of the composites with different weight ratios of RHA have been shown in figure 11. First of all, Alaneme and Olubambi [52] have noticed that the value of friction coefficient increases for starting period of $120 \mathrm{~s}$ due to localized bonding of the wear surface with the counterface during initial run-in-period. Also, the friction coefficient has been found to be maximum for $\mathrm{Al}-\mathrm{Mg}-\mathrm{Si} / 6 \% \mathrm{Al}_{2} \mathrm{O}_{3} / 4 \% \mathrm{RHA}$ hybrid composite compared with hybrid composites (with 2 wt.\% and 3 wt.\% RHA content) and ceramic reinforced composite (Al-Mg-Si/10\% $\mathrm{Al}_{2} \mathrm{O}_{3}$ composite). Also, the friction coefficient of hybrid composites with higher percentage of RHA ( 3 and 4 wt.\%) increases with time, while it remains constant for $10 \% \mathrm{Al}_{2} \mathrm{O}_{3}$ reinforced composite for the whole period of wear test. These results have been supported by the hardness values for all the composites, which is highest for single reinforced (Al-Mg-Si matrix10 wt. $\% \mathrm{Al}_{2} \mathrm{O}_{3}$ ) composite. Thus, it will undergo less plastic deformation and will exhibit lower friction coefficient as compared to the hybrid composites. The SEM analysis of the worn surfaces of composites has been conducted by Alaneme and Olubambi [52] as shown in figure 12. In figure 12(a), abrasion has been found to be predominant wear mechanism in the $10 \% \mathrm{Al}_{2} \mathrm{O}_{3}$ reinforced composite with a few signs of adhesion of removed debris with the wear surface. In case of 4 wt.\%RHA reinforced hybrid composites shown in figure 12(b), large welding of the debris on the wear surface has been observed that is indication of the adhesive wear mechanism. Therefore, friction coefficient for $4 \mathrm{wt} \% \mathrm{RHA}-6 \mathrm{wt} . \% \mathrm{Al}_{2} \mathrm{O}_{3}$ reinforced hybrid composites has been found to be considerably 

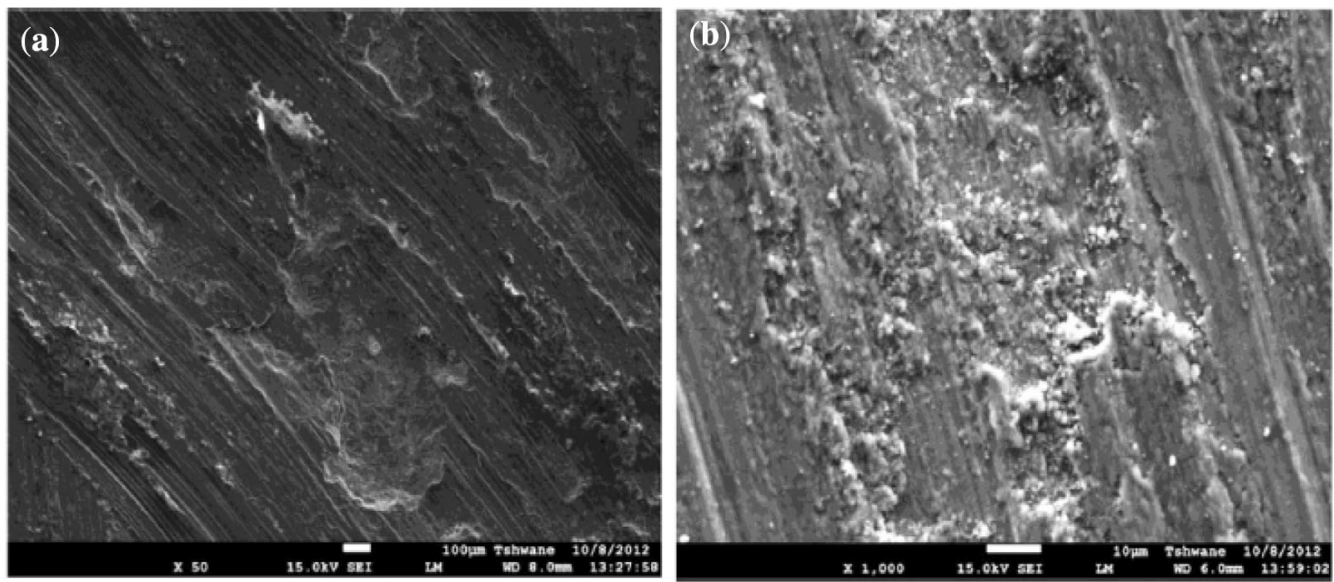

Figure 12. SEM analysis of Al-Mg-Si composites reinforced with (a) 10 wt. $\% \mathrm{Al}_{2} \mathrm{O}_{3}$, (b) 4 wt. $\%$ RHA-6 wt. $\% \mathrm{Al}_{2} \mathrm{O}_{3}$ [52]. Reproduced with permission from copyright owner.

large. The wear mechanism of the Al-composites was observed to transform from predominant abrasive wear to adhesive wear with an increase in RHA wt.\%.

\section{Al/Ceramic/lubricant composites}

\subsection{Microstructure and mechanical properties}

Stojanovic et al [53] have fabricated A356/SiC/Gr hybrid composites using semi-solid casting process and the microstructure of the developed composites indicates that the matrix alloy has been adequately dispersed with $\mathrm{SiC}$ and Gr particles. The area of the composite surface without reinforcement particles has been decreased with an increase in the reinforcement content that is an indication of good dispersion of the particles within the matrix alloy. As the Gr-particles are soft in nature, thus it is difficult to maintain the mean size of these particles $(35 \mu \mathrm{m})$ during the casting process. Actually, the erosion and size reduction takes place during the mixing of hybrid reinforcements in the alloy melt. Pandiyarajan et al [54] have developed Al6061/ $\mathrm{ZrO}_{2} /$ $\mathrm{C}$ composites containing different reinforcement ratio of hybrid reinforcements using stir casting technique and the microstructure of the hybrid composites has been observed to be uniform. Figures 13(a) and (b) show the surface plots regarding variations in the mechanical properties of hybrid composites with respect to reinforcement percentage of $\mathrm{ZrO}_{2}$ and $\mathrm{C}$ particles. It has been found that microhardness and tensile strength of the hybrid composites attains a maximum value at a lower value of $C$ (lubricant) and higher value of $\mathrm{ZrO}_{2}$ (ceramics). This trend clearly shows that the addition of $\mathrm{C}$ makes the HAMCs softer because $\mathrm{C}$ acts as solid lubricant. But, addition of $\mathrm{ZrO}_{2}$ ceramic particles improves the load bearing capacity of the composites. However, no clear relation between the output response and reinforcement fractions of $\mathrm{ZrO}_{2}$ and $\mathrm{C}$ particles has been observed in the plots, which is an indication of the interaction of these parameters. The composites show different trend in mechanical properties with respect to one parameter (percentage of one reinforcement) depending upon the
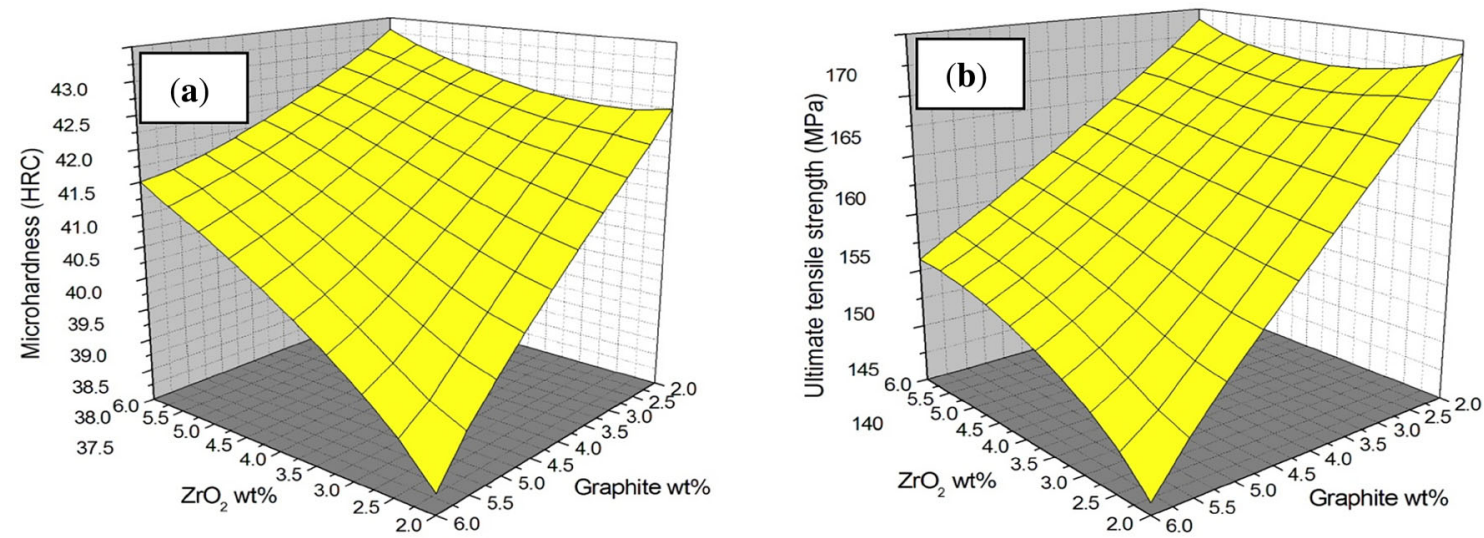

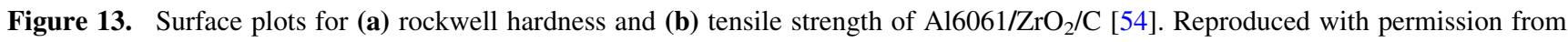
Springer 2017. 
value of other parameter (percentage of other reinforcement). The addition of minimum percentage of ceramic reinforcement has significant influence on the mechanical properties as observed from the wider zone of the surface plots in the experimental study.

\subsection{Wear properties}

According to Siva Sankara Raju et al [49], the wear resistance of the Al-1100 composites reinforced with different materials is significantly higher than the alloy matrix (figure 14). In this study, the composite pins rubbed against the steel disc (EN31) under different magnitude of load $(10-60 \mathrm{~N})$. The transition in the wear mechanism of the alloy (from mild to severe) was observed at a critical load of $30 \mathrm{~N}$, while no such transitions have been observed in the composite specimen. This is due to the severe deformation of the soft metallic alloy by the hard counterface. Further, it has been noticed that $\mathrm{Al} / \mathrm{CSA}$ and $\mathrm{Al} / \mathrm{Al}_{2} \mathrm{O}_{3}$ composites possess similar wear resistance. But, presence of Gr-lubricant particles has significant influence on the wear resistance of the hybrid composites due to which $\mathrm{Al} /$ $\mathrm{CSA} / \mathrm{Gr}$ and $\mathrm{Al} / \mathrm{Al}_{2} \mathrm{O}_{3} / \mathrm{Gr}$ hybrid composites possess superior wear resistance. The Gr-particles forms a thin lubricant film on the wear surface and thus reduces the metallic contact between sliding surfaces. In overall, lowest wear rate has been observed in $\mathrm{Al} / \mathrm{CSA} / \mathrm{Gr}$ composites due to presence of lubricant $(\mathrm{Gr})$ and alkali materials $(\mathrm{CaO}$ and $\mathrm{MgO}$ ) in CSA. The alkali materials act as heat resistant elements in the composites and reduce the effect of thermal softening in the hybrid composites. The SEM analysis shows that depth and width of the grooves formed on the worn surface of $\mathrm{Al} / \mathrm{CSA} / \mathrm{Gr}$ composite are relatively less in comparison to other composites under same sliding conditions.

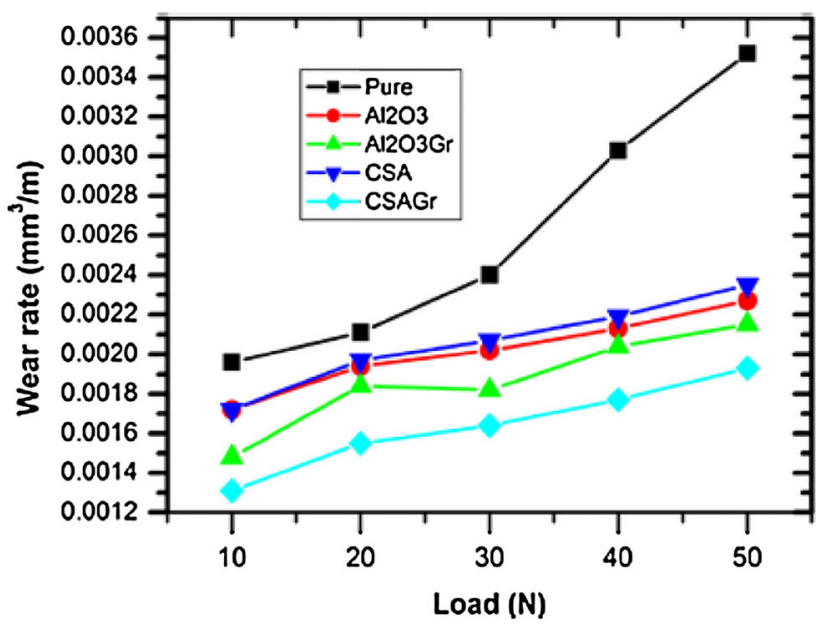

Figure 14. Wear rate of the Al-1100 composites vs. applied load [49]. Reproduced with permission from Springer 2017.
On the other hand Stojanovic et al [53] have found that the wear resistance of the $\mathrm{Al} 356 / 10 \% \mathrm{SiC} /(1-3 \%) \mathrm{Gr}$ hybrid composites is superior to $\mathrm{Al} 356 / 10 \% \mathrm{SiC}$ composites. The wear behaviour of the composites was studied on computer based block-on-disc tribometer according to ASTM G77-83 standard. The wear rate was calculated using the geometry of wear scar observed in a SEM micrograph. Further, addition of $1 \mathrm{wt} \%$ of Gr-particles reduced the wear rate of the hybrid composites followed by an increasing trend up to 3 wt. \% of reinforcement content. The reduction in the wear rate of composites with addition of $\mathrm{Gr}$ up to $1 \mathrm{wt} . \%$ is due to selflubricating nature of the hybrid composites. Beyond this reinforcement percentage of Gr-particles, fracture toughness of the hybrid composites is reduced that results in reduction in the wear resistance. The results obtained in this study are in line with other investigations conducted by Ravindran et al [56, 57], who found that there is an optimum percentage of Gr-reinforcement for obtaining maximum wear resistance of $\mathrm{Al} / \mathrm{SiC} / \mathrm{Gr}$ hybrid composites. In this study, applied load has been found to exhibit maximum influence $(38.99 \%)$ on the wear resistance of the hybrid composites followed by sliding speed (17.87\%), Gr percentage $(1395 \%)$ and sliding distance $(11.25 \%)$.

In an experimental study conducted by Pandiyarajan et al [54], addition of $\mathrm{ZrO}_{2}$ in the $\mathrm{Al} / \mathrm{ZrO}_{2} / \mathrm{C}$ composites results in increased rate of microcutting of the composites that is an indication of increased brittleness of the composites. Figures 15(a) and (b) show that the microcutting of the composites is increased with increase in content of $\mathrm{ZrO}_{2}$ for same C content. On the other hand, figures 15(a) and (c) also show that microploughing is the predominant wear mechanism at higher reinforcement content of the softer phase (C) in the hybrid composites for same $\mathrm{ZrO}_{2}$ particles. Actually, wear behaviour of the hybrid composites has been found to be dependent on the microhardness value. The addition of $\mathrm{C}$ reduces the microhardness of the composites, while $\mathrm{ZrO}_{2}$ is hard phase that increases microhardness of the composite specimens. Therefore, wear rate is reduced with an increase in wt. $\%$ of $\mathrm{ZrO}_{2}$ and decrease in wt. $\%$ of $\mathrm{C}$. The increased ploughing of the wear surface at higher $\mathrm{C}$ content has been attributed to increased ductility of the composite specimens. On the other hand, the composite surface undergo increased microcutting at higher $\mathrm{ZrO}_{2}$ content due to increased toughness and brittleness. Therefore, higher percentage (6 wt.\%) of both reinforcements results in increased plastic deformation of the hybrid composites as shown in figure 15(d). This indicates that the percentage of the hybrid reinforcements has significant influence on the wear behaviour of the hybrid composites.

Suresha and Sridhara [55] have found that hybrid composites are reinforced with $\mathrm{SiC}$ and lubricant (Gr) particulates exhibit improved wear performance under sliding wear conditions. The hard particles increase the hardness and resistance to sliding wear, while soft particles provide requisite lubrication in order to reduce friction coefficient and wear rate. A protective surface layer has been observed 

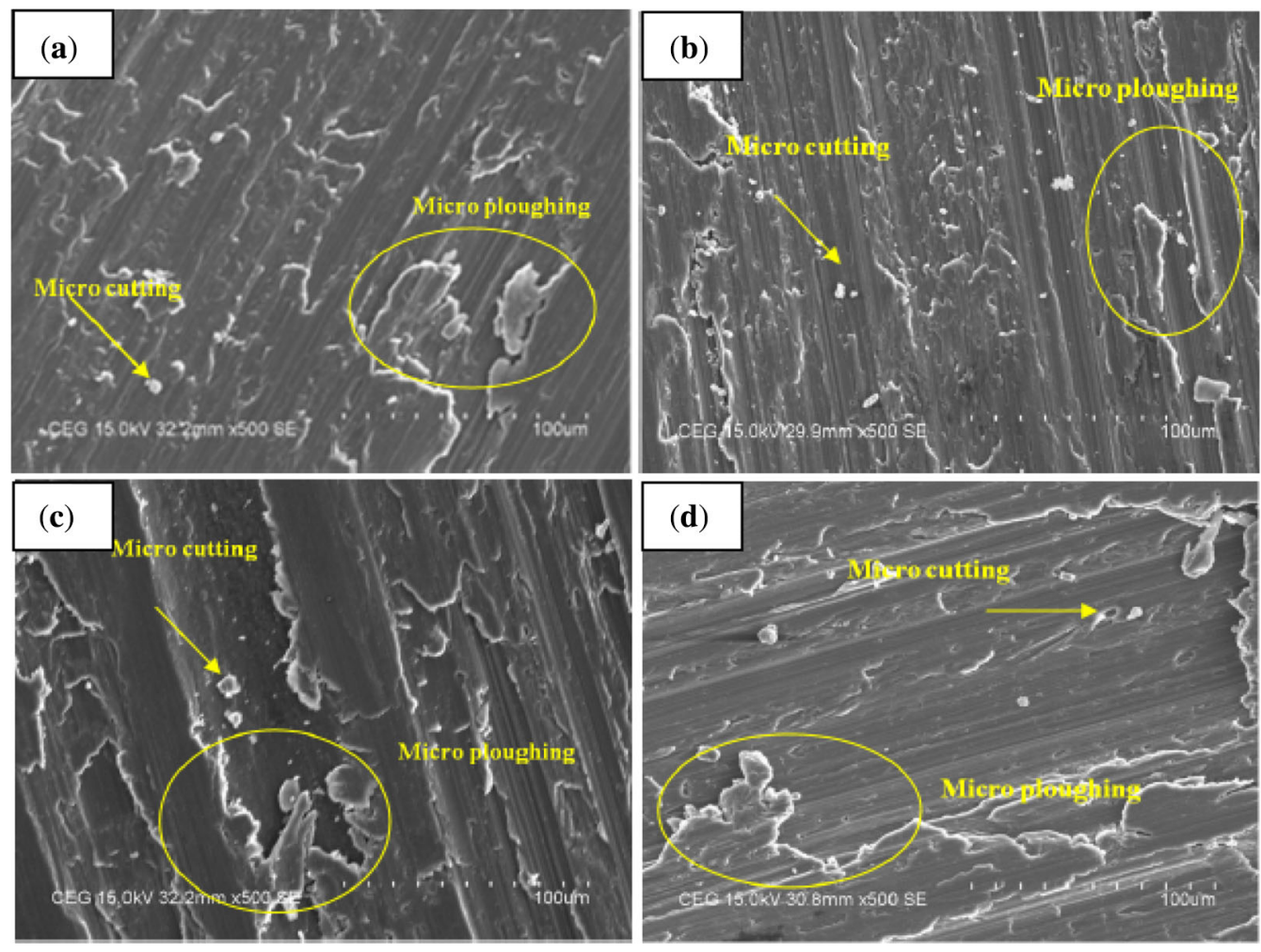

Figure 15. SEM image of worn surface of (a) $\mathrm{Al}-2 \% \mathrm{ZrO}_{2} / 2 \% \mathrm{C}$, (b) $\mathrm{Al}-6 \% \mathrm{ZrO}_{2} / 2 \% \mathrm{C}$, (c) $\mathrm{Al}-2 \% \mathrm{ZrO}_{2} / 6 \% \mathrm{C}$, and (d) $\mathrm{Al}-6 \% \mathrm{ZrO}{ }_{2} / 6 \% \mathrm{C}$ [54]. Reproduced with permission from Springer 2017.

between the pin and the counterface due to incorporation of graphite particles in the aluminium matrix. This behavior may be due to the fact that the Gr-particles act as solid lubricant and reduce friction between rubbing surfaces, while the ceramic particles are quite hard and reduce abrasion of the wear surface. It was reported that the wear of composites decreased with an increase in the percentage of reinforcement and sliding speed. With increasing load and sliding distance, the wear of the composites has been found to increase due to increase in metal-to-metal contact at the interface. With addition of solid lubricant i.e., Grparticles, the wear of the composite tends to decrease. On the other hand, the presence of $\mathrm{SiC}$ is responsible for increase in the strength and the resistance to wear of composite while reducing machinability.

Kumar and Dhiman [58] fabricated hybrid composites to compare the specific wear rate of Al-7075 alloy and Al7075 composites reinforced with $7 \mathrm{wt} . \%$ of $\mathrm{SiC}$ and $3 \mathrm{wt} . \%$ of Gr-particles. The wear tests were conducted on a pin-ondisc test rig as per ASTM G99-05 standard and EN32 steel disc was used as a counterface material. The variations in the wear rate of the composite and alloy specimens with respect to load for all combinations of sliding speed and sliding distance have been shown in figure 16. It was reported that the specific wear rate of the hybrid composite was lower than that of unreinforced Al7075 alloy for all combinations of sliding parameters i.e., applied load of
20-40 N, sliding speed of 2-4 m/s and sliding distance of 2000-6000 m. Under low load $(20 \mathrm{~N})$ conditions, mild abrasive wear has been observed for both of the composite and alloy specimens. As the magnitude of load is increased to $40 \mathrm{~N}$, the wear of the alloy specimens was suddenly increased indicating the transition of the wear mechanism. However, no transition in the wear rate of the hybrid composites was observed at an increased load of $40 \mathrm{~N}$. At higher loads $(60 \mathrm{~N})$, significant plastic deformation has been observed on the surface of the alloy specimen due to thermal softening effect. The wear rate of the alloy has been found to be very large under high load conditions, which is an indication of delaminated wear and seizure. The transition from mild abrasive wear (fine scratches) to delaminated wear (distinct groves) has also been observed in composite specimens with increase in load from $40 \mathrm{~N}$ to $60 \mathrm{~N}$. The wear debris in the form of thin sheets has also been removed from the wear surface of the composites due to combined effect of high load and velocity. In spite of high wear rate, no seizure has been observed in case of hybrid composites. It has been noticed that a protective (oxide) layer has been formed between the sliding surface under moderate values of load and velocity. This is due to the reaction between the counterface disc, composites and environmental components [59-61]. This layer reduced the direct contact between the rubbing surfaces reducing the wear rate of the composites. These layers vanish under the 

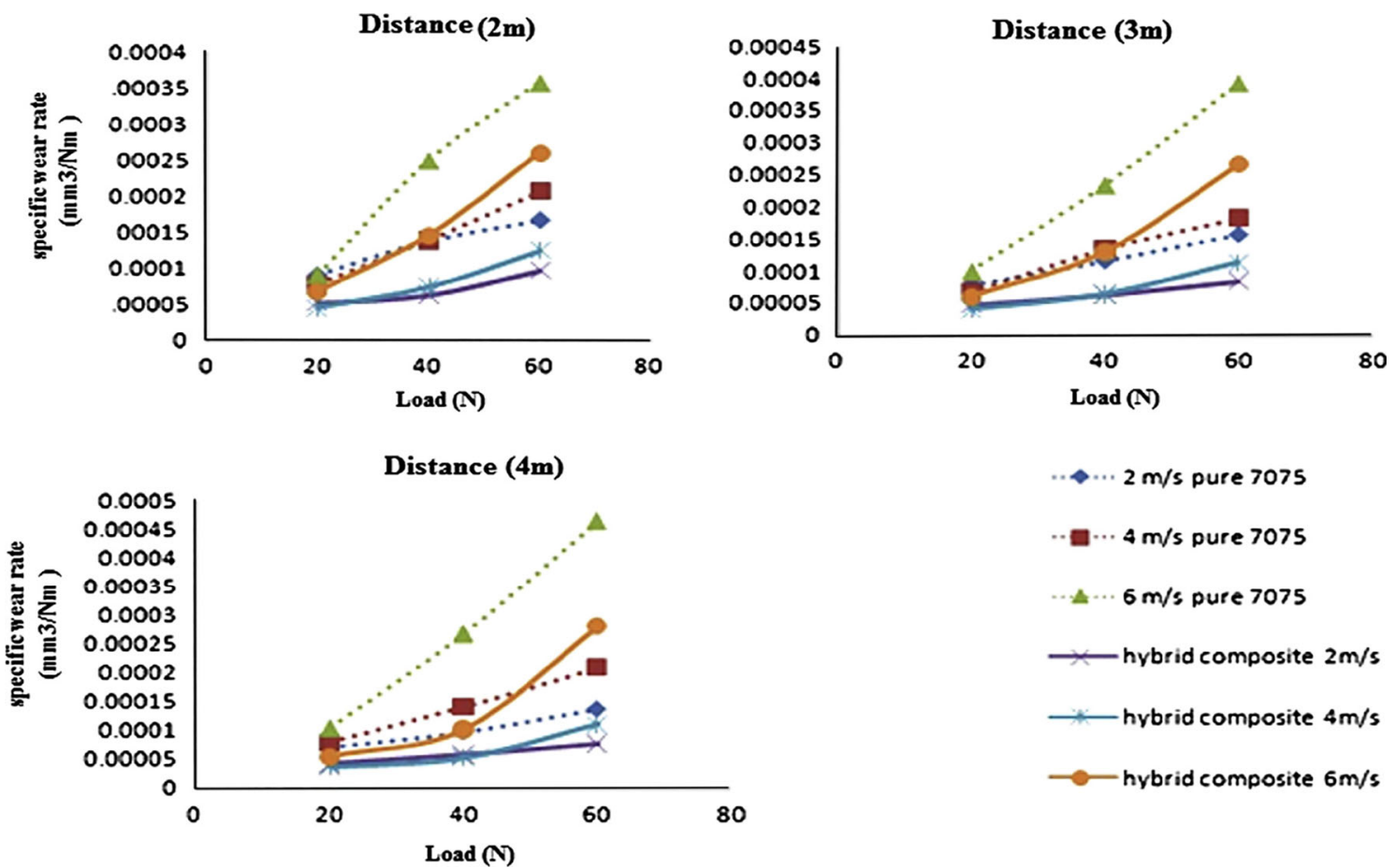

Figure 16. Specific wear rate of the Al7075 alloy and hybrid composites under different combination of parameters [58]. Reproduced with permission from Elsevier 2013.

action of severe load $(60 \mathrm{~N})$ and sliding velocity $(6 \mathrm{~m} / \mathrm{s})$ that increases wear rate of the hybrid composites. The wear rate of the Al7075 alloy and composites is reduced with increase in sliding distance from $2 \mathrm{~m} / \mathrm{s}$ to $4 \mathrm{~m} / \mathrm{s}$ at low load $(20-40 \mathrm{~N})$. At higher loads, the trend in the wear rate of both was reversed at higher loads (40-60 N) due to damage of tribolayers. The wear rate of the composite and alloy specimens were decreased for a higher sliding distance for low load $(20-40 \mathrm{~N})$ and low speed $(2-4 \mathrm{~m} / \mathrm{s})$ conditions. However, contradictory results have been observed with increase in sliding distance at high load and high speed conditions. In overall, the values of transition load and velocity for the hybrid composites have been found to be higher than that of the pure alloy that is an indication of improvement of the seizure resistance of the alloy with addition of hybrid reinforcements.

\section{Conclusions}

Currently, industrial organizations are focusing on utilization of light weight, low cost and high performance materials for designing various automotive components. The Albased hybrid composites have been found to be suitable for these requirements owing to their low weight and improved mechanical properties and wear resistance. Moreover, use of inexpensive reinforcement materials and fabrication technique reduces the cost of the hybrid composites. It has been reported that HAMCs reinforced with ceramics and inexpensive reinforcements exhibit superior mechanical and wear properties in comparison to the ceramics reinforced composites and the unreinforced Al-alloys. It has been revealed that addition of FA improves mechanical properties such as specific strength, hardness, impact strength and fatigue strength of the hybrid composites. Moreover, use of FA as a complementary reinforcement reduces the chances of formation of intermediate compounds in the $\mathrm{Al} / \mathrm{SiC} / \mathrm{FA}$ composites that improves the interfacial properties of these materials. It has also been revealed that an increase in RHA content reduces the weight and cost of the hybrid composites without compromising the mechanical properties. Also, addition of RM, $\mathrm{CSA}$ and $\mathrm{Gr}$ as a secondary reinforcement improves the specific wear resistance of the hybrid composites. The improved physical, mechanical and tribological properties especially low cost, high strength-to-weight ratio makes the HAMCs suitable for a number of automotive applications such as cylinder liners, pistons, connecting rods, cam shafts, rocker arms, bearings, brake drums, clutches and axles. However, different combinations of the reinforcements are required to be explored for development of HAMCs specific applications. This can be achieved by developing HAMCs using low cost processing route and investigating their properties under the influence of control parameters. 


\section{References}

[1] Macke A, Schultz B F and Rohatgi P 2012 Metal matrix composites offer the automotive industry an opportunity to reduce vehicle weight, improve performance. Adv. Mater. Process. 170: 19-23

[2] Miracle D B 2005 Metal matrix composites-from science to technological significance. Compos. Sci. Technol. 65: 526-540

[3] Simon S C and McMillan M L 2004 Automotive tribology overview of current advances and challenges for future. Tribol. Int. 37: 517-536

[4] Surappa M K 2003 Aluminum matrix composites: challenges and opportunities. Sadhana 28: 319-334

[5] Rohatgi P and Schultz B 2007 Light weight metal matrix composites- stretching the boundaries of metals. Mater. Matters 2: 16-19

[6] Sun C, Song M, Wang Z and He Y 2016 Effect of particle size on the microstructures and mechanical properties of SiC-reinforced pure aluminum composites. J. Mater. Eng. Perf. 20: $1606-1612$

[7] Cocen U and Onel K 2002 Ductility and strength of extruded SiCp/aluminium-alloy composites. Compos. Sci. Technol. 62: $275-282$

[8] Singh J 2016 Fabrication characteristics and tribological behavior of $\mathrm{Al} / \mathrm{SiC} / \mathrm{Gr}$ hybrid aluminum matrix composites: a review. Friction 4(3): 191-207

[9] Bains P S, Sidhu S S and Payal H S 2016 Fabrication and machining of metal matrix composites: a review. Mater. Manuf. Process. 31(5): 553-573

[10] Wang K, Li W, Du J, Tang P and Chen J 2016 Preparation, thermal analysis and mechanical propertied of in-situ $\mathrm{Al}_{2} \mathrm{O}_{3}$ / $\mathrm{SiO}_{2}$ ( $\mathrm{p}$ /Al composites fabricated by using zircon tailing sand. Mater. Des. 99: 303-316

[11] Guan L, Geng L, Zhang H and Huang L 2011 Effects of stirring parameters on microstructure and tensile properties of $\left(\mathrm{ABO}_{\mathrm{w}}+\mathrm{SiC}_{\mathrm{p}}\right) / 6061 \mathrm{Al}$ composites fabricated by semisolid stirring technique. Trans. Nonferr. Met. Soc. China 21(2): $274-279$

[12] Amirkhanlou S and Niroumand B 2012 Fabrication and characterization of $\mathrm{Al} 356 / \mathrm{SiCp}$ semisolid composites by injecting $\mathrm{SiCp}$ containing composite powders. J. Mater. Process. Technol. 212: 841-847

[13] Jebeen Moses J, Dinaharan I and Joseph Sekhar S 2016 Prediction of influence of process parameters on tensile strength of AA6061/TiC aluminum matrix composites produced using stir casting. Trans. Nonferr. Met. Soc. China 26(6): 1498-1511

[14] Rooy E L 1988 Aluminum and Aluminum Alloys, Metals Handbook, vol. 15, ASM Intrenational, Russell Township, pp. 743-770

[15] Moghadam A D, Schultz B F, Ferguson J B, Omrani E, Rohatgi P K and Gupta N 2014 Functional metal matrix composites: self-lubricating, self-healing, and nanocomposites-an outlook. JOM 66(6): 872-881

[16] Bahrami A, Soltani N, Pech-Canul M I and Gutierrez C A 2016 Development of metal matrix composites from industrial/agricultural waste materials and their derivatives. Crit. Rev. Env. Sci. Technol. 46(2): 143-208

[17] Lancaster L, Lung M H and Sujan D 2013 Utilization of agro-industrial waste in metal matrix composites: Towards sustainability. Int. J. Env. Ecolog. Geomat. Earth Sci. Eng. 7(1): 25-33

[18] Prasad S D and Krishna R A 2011 Production and mechanical properties of A356.2/RHA composites. Int. J. Adv. Sci. Technol. 33: 51-58

[19] Zuhailawati H, Samayamutthirian P and Mohd Haizu C H 2007 Fabrication of low cost aluminum matrix composite reinforced with silica sand. J. Phys. Sci. 18: 47-55

[20] Kanthavel K, Sumesh K R and Saravanakumar P 2016 Study on tribological properties on $\mathrm{Al} / \mathrm{Al}_{2} \mathrm{O}_{3} / \mathrm{MoS}_{2}$ hybrid composite processed by powder metallurgy. Alex. Eng. J. 55(1): 13-17

[21] Baradeswaran A and Perumal A E 2016 Wear and mechanical characteristics of Al 7075/graphite composites. Compos. B Eng. 56: 472-476

[22] Baradeswaran A and Perumal A E 2014 Study on mechanical and wear properties of $\mathrm{Al} 7075 / \mathrm{Al}_{2} \mathrm{O}_{3} /$ Graphite hybrid composites. Compos. B Eng. 56: 464-471

[23] Singh J and Chauhan A 2014 A review on sliding wear behaviour of aluminium matrix composites with hybrid reinforcements for automotive applications. Tribol. Online 9(3): 121-134

[24] Singh J and Chauhan A 2014 Overview of aluminium matrix composites for automotive applications. Int. J. Appl. Eng. Res. 9(8): 959-966

[25] Singh J and Chauhan A 2016 Characterization of hybrid aluminum matrix composites for advanced applications-a review. J. Mater. Resear. Technol. 5(2): 159-169

[26] Singh J and Chauhan A 2016 Overview of wear performance of aluminium matrix composites reinforced with ceramic materials under the influence of controllable variables. Ceram. Int. 42(1): 56-81

[27] Tan M, Xin Q, Li Z and Zong B Y 2001 Influence of SiC and $\mathrm{Al}_{2} \mathrm{O}_{3}$ particulate reinforcements and heat treatments on mechanical properties and damage evolution of Al-2618 metal matrix composites. J. Mater. Sci. 36(8): 2043-2054

[28] Das D K, Mishra P C, Singh S and Thakur R K 2014 Properties of ceramic-reinforced aluminium matrix composites-a review. Int. J. Mech. Mater. Eng. 9(1): 1-16

[29] Rajan T P D, Pillai R M, Pai B C, Satyanarayana K G and Rohatgi P K 2007 Fabrication and characterisation of Al$7 \mathrm{Si}-0.35 \mathrm{Mg} /$ fly ash metal matrix composites processed by different stir casting routes. Compos. Sci. Technol. 67: 3369-3377

[30] Suresh N, Venkateswara S and Seetharamu S 2010 Influence of cenosphere of Fly ash on the mechanical and wear of permanent moulded eutectic Al-Si alloys. Mater. Sci. Pol. 28(1): 55-65

[31] Rohatgi P K and Guo R Q 1997 Low cost cast aluminium-fly ash composites for ultra-light automotive applications. Fuel. Energy Abstr. 38(5): 319

[32] Feng Y, Liu D, Li D and Zhao Q 2017 A study on microstructure composition of unsaturated red mud and its impact on hydraulic characteristics. Geotech. Geol. Eng. 35: 1357-1367

[33] Prasad N, Sutar H, Mishra S C, Sahoo S K and Acharya S K 2013 Dry sliding wear behaviour of aluminium matrix composite using red mud an industrial waste. Int. Res. J. Pure Appl. Chem. 3(1): 59-74

[34] Usman A M, Raji A, Waziri N H et al (2014) Aluminium alloy rice husk ash composites production and analysis. Leonardo Electron J. Prac. Technol. 3(25):84-98 
[35] Rodrigues C S, Ghavami K and Stroeven P 2010 Rice Husk Ash as a Supplementary Raw Material for the Production of Cellulose-Cement Composites with Improved Performance. Waste Biomass Valor. 1: 241-249

[36] Madakson P B, Yawas D S and Apasi A 2012 Characterization of coconut shell ash for potential utilization in metal matrix composites for automotive applications. Int. J. Eng. Sci. Technol. 4(3): 1190-1198

[37] Olugbenga O A and Akinwole A A 2010 Characteristics of bamboo leaf ash stabilization on lateritic soil in highway construction. Int. J. Eng. Technol. 2(4): 212-219

[38] David Raja S J, Dinaharan I and Robinson Smart D S 2013 Synthesis and characterization of Al6061-Fly $\mathrm{Ash}_{\mathrm{p}}-\mathrm{SiC}_{\mathrm{p}}$ composites by stir casting and compocasting methods. Energy Proc. 34:637-646

[39] Dwivedi S P, Sharma S and Mishra R K 2015 Microstructure and mechanical behavior of A356/SiC/Fly-ash hybrid composites produced by electromagnetic stir casting. J. Braz. Soc. Mech. Sci. Eng. (2015) 37: 57-67

[40] Chawla N and Shen Y L 2001 Mechanical behaviour of particulate reinforced metal matrix composites. Adv. Mater. Process. 3(6): 357-370

[41] Singh J and Chauhan A 2017 Fabrication characteristics and tensile strength of novel Al2024/SiC/red mud composites processed via stir casting route. Trans. Nonferr. Met. Soc. China 27:2573-2586

[42] Kumar M and Megalingam A 2017 Tribological characterization of Al6061/alumina/graphite/redmud hybrid composite for brake rotor application. Particul. Sci. Technol. DOI: 10.1080/02726351.2017.1367747

[43] Singh J and Chauhan A 2017 Influence of reinforcement parameters and ageing time on mechanical behavior of novel Al2024/SiC/red mud composites using response surface methodology. JOM 69(12): 2471-2479

[44] Kurapati V B, Kommineni R and Sundarrajan S 2018 Statistical analysis and mathematical modeling of dry sliding wear parameters of 2024 aluminium hybrid composites reinforced with fly ash and $\mathrm{SiC}$ particles. Trans. Ind. Inst. Met. 71(7): 1809-1825

[45] Deuis RL, Subramanian C and Yellup J M 1997 Dry sliding wear of aluminium composites-a review. J. Compos. Sci. Technol. 5: 415-435

[46] Prasad D S, Shoba C and Ramanaiah N 2014 Investigations on mechanical properties of aluminum hybrid composites. $J$. Mater. Resear. Technol. 3(1): 79-85

[47] Alaneme K K, Akintundea I B, Olubambib P A and Adewalec T M 2013 Fabrication characteristics and mechanical behaviour of rice husk ash-Alumina reinforced $\mathrm{Al}-\mathrm{Mg}-\mathrm{Si}$ alloy matrix hybrid composites. J. Mater. Resear. Technol. 2(1): 60-67

[48] Alaneme K K, Ademilua B O and Bodunrin M O 2013 Mechanical properties and corrosion behaviour of aluminium hybrid composites reinforced with silicon carbide and bamboo leaf Ash. Tribol. Ind. 35(1): 25-35

[49] Siva Sankara Raju R, Panigrahi M K, Ganguly R I and Srinivasa Rao G 2017 Investigation of tribological behavior of a novel hybrid composite prepared with Al-coconut shell ash mixed with graphite. Metall. Mater. Trans. A 48: 3892-3903

[50] Prasad D S and Shoba C 2014 Hybrid composites-a better choice for high wear resistant materials. J. Mater. Resear. Technol. 3(2): 172-178

[51] Alaneme K K, Tolulope M A and Peter A O 2014 Corrosion and wear behaviour of Al-Mg-Si alloy matrix hybrid composites reinforced with rice husk ash and silicon carbide. $J$. Mater. Resear. Technol. 3(1): 9-16

[52] Alaneme K K and Olubambi P A 2013 Corrosion and wear behaviour of rice husk ash-alumina reinforced $\mathrm{Al}-\mathrm{Mg}-\mathrm{Si}$ alloy matrix hybrid composites. J. Mater. Resear. Technol. 2(1): 188-194

[53] Stojanovic B, Babic M, Velickovic S and Blagojevic J 2016 Tribological behavior of aluminum hybrid composites studied by application of factorial techniques. Tribol. Trans. 59(3): 522-529

[54] Pandiyarajan R, Marimuthu S and Ganesh K C 2017 Mechanical and tribological behavior of the metal matrix composite AA6061/ZrO2/C. J Mech. Sci. Technol. 31(10): 4711-4717

[55] Suresha S and Sridhara B K 2010 Effect of silicon carbide particulates on wear resistance of graphitic aluminium matrix composites. Mater. Des. 31(9): 4470-4477

[56] Ravindran P, Manisekar K, Narayanasamy R and Narayanasamy P 2013 Tribological behaviour of powder metallurgy - processed aluminium hybrid composites with the addition of graphite solid lubricant. Ceram. Int. 39(2): 1169-1182

[57] Ravindran P, Manisekar K, Narayanasamy R and Narayanasamy P 2012 Application of factorial techniques to study the wear of Al hybrid composites with graphite addition. Mater. Des. 39: 42-54

[58] Kumar R and Dhiman S 2013 A study of sliding wear behaviours of Al-7075 and al-7075 hybrid composites by response surface methodology analysis. Mater. Des. 50: 351-359

[59] Venkataraman B and Sundararajan G 2000 Correlation between the characteristics of the mechanically mixed layer and wear behavior of aluminum Al-7075 alloy and AlMMCs. Wear 245: 22-38.

[60] Singh J and Chauhan A 2018 Investigations on dry sliding frictional and wear characteristics of $\mathrm{SiC}$ and red mud reinforced Al2024 matrix hybrid composites using Taguchi's approach. Proc. IMech. Eng. L J. Mater. Des. Appl. https://doi.org/10.1177/1464420718803126.

[61] Pai B C 1995 Review-role of magnesium in cast aluminum alloy matrix composites. J. Mater. Sci. 30: 1903-1911. 